\title{
Productivity and the Decision to Import and Export: Theory and Evidence*
}

\author{
Hiroyuki Kasahara ${ }^{\dagger} \quad$ Beverly Lapham ${ }^{\ddagger}$
}

\begin{abstract}
This paper develops an open economy model with heterogeneous final goods producers who simultaneously choose whether to export their goods and whether to use imported intermediates. The model highlights mechanisms whereby import policies affect aggregate productivity, resource allocation, and industry export activity along both the extensive and intensive margins. Using the theoretical model, we develop and estimate a structural empirical model that incorporates heterogeneity in productivity and shipping costs using Chilean plant-level data for a set of manufacturing industries. The estimated model is consistent with the key features of the data regarding productivity, exporting, and importing. We perform a variety of counterfactual experiments to assess quantitatively the positive and normative effects of barriers to trade in import and export markets. These experiments suggest that there are substantial aggregate productivity and welfare gains due to trade. Furthermore, because of import and export complementarities, policies which inhibit the importation of foreign intermediates can have a large adverse effect on the exportation of final goods.
\end{abstract}

Keywords: exporting, importing, firm heterogeneity, aggregate productivity, resource allocation JEL Classification Numbers: O40, F12, E23, C23.

\footnotetext{
${ }^{*}$ We thank Martin Boileau, Allen Head, Sam Kortum, Lance Lochner, Ricardo Lopez, Scott Taylor, John Whalley, and seminar participants at North American Meeting of Econometric Society, Canadian Macroeconomics Study Group, Southern Economic Association, Vienna Macroeconomics Workshop, World Congress of Econometric Society, Canadian Economics Association, Society for Economic Dynamics, Queen's University, University of Calgary, University of Western Ontario, Universitat de Pompeu Fabra, and Humboldt University. This work was made possible by the facilities of the Shared Hierarchical Academic Research Computing Network (SHARCNET:www.sharcnet.ca). Lapham gratefully acknowledges financial support from the Social Sciences Humanities Council of Canada.

${ }^{\dagger}$ Department of Economics, University of Western Ontario, London, Ontario, Canada N6A 5C2; hkasahar@uwo.ca; 519-661-2111, ext. 85461.

${ }^{\ddagger}$ Corresponding Author. Department of Economics, Queen’s University, Kingston, Ontario, Canada K7L 3N6; laphamb@econ.queensu.ca; 613-533-2297.
} 


\section{Introduction}

This paper develops and estimates a stochastic industry model of heterogeneous firms which may export output and import inputs. We use Chilean plant-level data for a set of manufacturing industries to estimate the model. The estimated models are used to perform counterfactual experiments regarding different trading regimes to assess the effects of barriers to trade in import and export markets on productivity, resource allocation, and welfare.

Previous empirical work suggests that there is a substantial degree of resource reallocation across firms within an industry following trade liberalization and these shifts in resources contribute to productivity growth. Pavcnik (2002) uses Chilean data and finds such reallocations and productivity effects after trade liberalization in that country. Trefler (2004) estimates these effects in Canadian manufacturing following the U.S.-Canada free trade agreement using plantand industry-level data and finds significant increases in productivity among both importers and exporters.

Empirical evidence also suggests that relatively more productive firms are more likely to export. ${ }^{1}$ In this paper we provide empirical evidence consistent with this observation and additional evidence suggesting that whether or not a firm is importing intermediates for use in production is also important for explaining differences in plant performance. ${ }^{2}$ In particular, our data suggests that firms which both import intermediates and export their output tend to be larger and more productive than firms that are active in either market, but not both. Hence, the impact of trade on resource reallocation across firms which are importing may be as important as shifts across exporting firms.

Melitz (2003), motivated by the empirical findings regarding exporters described above, develops a monopolistic competition model of exporters with different productivities and examines the effect of trade liberalization. ${ }^{3}$ To address simultaneously the empirical regularities concern-

\footnotetext{
${ }^{1}$ See, for example, Aw, Chung, and Roberts (2000), Bernard and Jensen (1999), Bernard, et al. (2003), Clerides, Lack and Tybout (1998), and Eaton, Kortum, and Kramarz (2004a). Other observations on firm level exports include: (a) a majority of firms do not export, (b) most exporters only export a small fraction of their output, and (c) most exporters only export to a small number of countries.

${ }^{2}$ See also Amiti and Konings (2005), Halpern, Korn, and Szeidl (2006), and Kasahara and Rodrigue (2005) for evidence of a positive relationship between importing inputs and productivity. Few empirical studies simultaneously examine both exports and imports at the micro-level. A notable exception is Bernard, Jensen, and Schott (2005) who provide empirical evidence regarding both importers and exporters in the U.S.

${ }^{3}$ Several alternative trade theories with heterogeneous firms have been developed as well. Eaton and Kortum (2002) develop a Ricardian model of trade with firm-level heterogeneity. Eaton, Kortum, and Kramarz (2004b) explore a model that nests both the Richardian framework of Eaton and Kortum and the monopolistic competition approach of Melitz. Helpman, Melitz, and Yeaple (2004) present a monopolistic competition model with heterogeneous firms that focuses on the firm's choice between exports and foreign direct investment. Bernard, Redding, and Schott (2007) develop a model of endowment-driven comparative advantage with heterogeneous
} 
ing firms which import intermediates, we extend his model to incorporate imported intermediate goods. In the model, the use of foreign intermediates increases a firm's productivity (because of increasing returns) but, due to fixed costs of importing, only inherently highly productive firms import intermediates. Thus, a firm's productivity affects its participation decision in international markets (i.e. importing inputs and/or exporting output) and, conversely, this participation decision (i.e. importing inputs) affects its productivity. We also extend Melitz' (2003) model to allow for sunk costs of trade, differences across firms in international transportation costs, and plant-specific cost and trade shocks.

We then provide a structural estimation of the stationary equilibrium of the model using a panel of Chilean plants for six manufacturing industries (Wearing Apparel, Plastic Products, Food Products, Textiles, Wood Products, and Fabricated Metals). The data is well-suited for our study as Chile underwent a significant trade liberalization from 1974-1979 but had fairly stable trade policies, and savings, investment, and growth rates during our sample period from 1990-1996. Furthermore, a significant portion of Chilean imports are in chemicals, electrical machinery, and heavy industrial machinery which is consistent with our focus on imported intermediate inputs.

We find that the estimated model replicates the observed patterns of productivity across plants with different import and export status as well as the observed distribution of export and import intensities. It is also consistent with the high degree of trade concentration among a small number of plants in our data. Furthermore, the inclusion of sunk costs and other features of the model allows us to capture the high degree of persistence in a plant's export and import status apparent in the data.

Regarding productivity, we find that the estimated mean of the productivity distribution at the steady state is significantly higher than the estimated mean at entry for each of our industries, suggesting that selection through endogenous exit plays an important role in determining industry productivity. Furthermore, the estimated model indicates that firms with high productivity and low international transportation costs tend to self-select into exporting and importing. Hence, heterogeneity in both productivity and shipping costs are significant in determining export and import status.

To examine the effects of trade policies, we perform a variety of counterfactual experiments that explicitly take into account equilibrium price adjustments. The experiments suggest that firms to examine both across and within industry reallocations in response to trade liberalization. Atkeson and Burstein (2007) examine firms' decisions to export and innovate in a dynamic, general equilibrium model. 
the welfare gains in moving from autarky to trade are substantial, with increases in real aggregate income ranging from 3-24 percent across the industries in our study. Furthermore, we estimate that industry total factor productivity increases between 5-14 percent when trade is liberalized. Another important finding from these experiments is that because of importing and exporting complementarities, policies which prohibit the importation of foreign intermediates can have a large adverse effect on the exportation of final goods, causing exports to fall significantly in each of the industries we study.

Our paper is a contribution to the recent empirical literature which seeks to provide structural estimation of international models with heterogeneous firms using plant-level data to examine the quantitative implications of trade policies. For instance, Das, Roberts, and Tybout (2007) use Columbian plant-level data for three manufacturing industries to examine the effects of trade liberalization and export subsidies on exports. Halpern, Koren, and Szeidl (2007) use a panel of Hungarian firms to explore relationships between importing and plant productivity. Using Indonesian data, Rodrigue (2008) estimates a model with foreign direct investment and exporting. Our results complement these papers but include analysis on the interaction between importing and exporting, sunk costs, and plant-specific shocks.

The remainder of the paper is organized as follows. Section 2 describes the Chilean manufacturing plant-level data we use and presents statistics from the industries regarding exporting and importing behavior. Section 3 presents the model while Section 4 provides details and results of the structural estimation of the model. Section 5 concludes.

\section{The Data}

Our data set is based on the Chilean manufacturing census for 1990-1996 which covers all plants with at least 10 employees. ${ }^{4}$ We examine two 4-digit level and four 3-digit level manufacturing industries. The list of industries and some descriptive statistics are given in Tables 1 and $2 .{ }^{5}$ As

\footnotetext{
${ }^{4} \mathrm{~A}$ detailed description of the data as well as Chilean industry trade orientation up to 1986 is found in Liu (1993), Tybout (1996), and Pavcnik (2002). The original data set is available from 1979 to 1996 but the value of export sales is reported only after 1990 and, thus, we exclude the period before 1990. The unit of observation in the data is a plant not a firm, and data for plants with less than 10 employees is not available. This data limitation may affect our results because plants that shrink to less than 10 employees will be listed as exiting in our data set and small existing plants that expand beyond 10 employees will be counted as entrants. Furthermore, we are unable to capture the extent to which multi-plant firms make joint decisions on exporting and importing across different plants they own. Neither are we able to examine whether or not a plant belongs to a multinational firm although exporting and importing by multinational firms are important topics (e.g., Helpman et al., 2004; Yi, 2003). Pavcnik (2002) reports that over 90 percent of manufacturing firms had only one plant for 1979-1986.

${ }^{5}$ The first two industries in Table 1 are 4-digit level industries while the last four industries are 3-digit level. In the data set, we observe the number of blue-collar workers and white-collar workers, the value of total sales,
} 
can be seen from Table 1, these industries are relatively large in sample size and include many plants that export and/or import. This table also demonstrates that a relatively large fraction of industry output is accounted for by firms which engage in international trade. Furthermore, among the firms that trade, those which both export goods and import intermediate inputs account for a significant fraction of trade volume and output.

Table 1: Descriptive Statistics for Exporters and Importers

\begin{tabular}{l|c|c|c|c|c|c}
\hline $\begin{array}{l}\text { \% of Industry Total } \\
\text { (1990-1996 Average ) }\end{array}$ & $\begin{array}{c}\text { Wearing } \\
\text { Apparel }\end{array}$ & $\begin{array}{c}\text { Plastic } \\
\text { Products }\end{array}$ & $\begin{array}{c}\text { Food } \\
\text { Products }\end{array}$ & Textiles & $\begin{array}{c}\text { Wood } \\
\text { Products }\end{array}$ & $\begin{array}{c}\text { Fabricated } \\
\text { Metals }\end{array}$ \\
\hline Number of Exporters & 5.1 & 5.1 & 28.2 & 7.0 & 17.8 & 4.4 \\
Number of Importers & 14.9 & 24.7 & 11.0 & 21.4 & 2.2 & 15.0 \\
Number of Ex/Importers & 7.7 & 19.2 & 12.9 & 14.0 & 4.9 & 9.0 \\
\hline Exports by Exporters & 10.0 & 16.0 & 51.6 & 17.1 & 58.2 & 16.1 \\
Exports by Ex/Importers & 90.0 & 84.0 & 48.4 & 82.9 & 41.8 & 83.9 \\
Imports by Importers & 36.5 & 39.2 & 55.4 & 29.3 & 20.2 & 36.6 \\
Imports by Ex/Importers & 63.5 & 60.8 & 44.6 & 70.7 & 79.8 & 63.4 \\
\hline Output by Exporters & 8.7 & 5.0 & 6.2 & 9.3 & 35.8 & 6.2 \\
Output by Importers & 18.6 & 29.9 & 22.6 & 20.4 & 2.6 & 22.8 \\
Output by Ex/Importers & 39.9 & 45.9 & 34.4 & 49.1 & 31.1 & 39.3 \\
\hline \hline Number of Plants & 534 & 369 & 857 & 530 & 561 & 642 \\
\hline
\end{tabular}

Notes: Exporters refers to plants that export but do not import intermediates. Importers refers to plants that import intermediates but do not export. Ex/Importers refers to plants that both export and import.

Turning to Table 2, we note that the standard deviations across plants for total sales and inputs suggests well-known heterogeneity in productivity across plants within a narrowly defined industry. Furthermore, export and import intensities differ across trading plants within an industry. These findings motivate us to include elements in our model below which generate heterogeneities across plants with respect these characteristics. Finally, we note that this table indicates that average gross profit margins were relatively stable between 1990 and 1996, consistent with the constant mark-ups we incorporate into our model.

Table 3 reports the number of plants in each industry that change their export and/or import status and the number of firms which enter and exit on average over our sample period. The table demonstrates that a substantial number of plants change their export/import status in each industry. As we discuss in Section 4, this observed within-plant variation in export and import status is important for identifying the sunk costs of exporting or importing separately from ongoing fixed costs of trade in our model. We also note that there was substantial plant

the value of export sales, the value of intermediate inputs, and the value of imported intermediate inputs for each plant (among other variables.) We deflate sales and expenditure on inputs by the industry-level output price deflator to convert nominal series into real terms. A plant's export and import status is identified from the data by checking if the value of export sales and the value of imported materials, respectively, are zero or positive. 
Table 2: Descriptive Statistics in 1990 and 1996

\begin{tabular}{|c|c|c|c|c|c|c|c|}
\hline \multicolumn{2}{|l|}{ Industry } & $\begin{array}{l}\text { Total } \\
\text { Sales }^{a}\end{array}$ & $\begin{array}{l}\text { Intermediate } \\
\text { Inputs }^{a}\end{array}$ & Labour & $\begin{array}{c}\text { Export } \\
\text { Intensity }^{b}\end{array}$ & $\begin{array}{l}\text { Import } \\
\text { Intensity }^{b}\end{array}$ & $\begin{array}{c}\text { Gross } \\
\text { Profit Margin }\end{array}$ \\
\hline \multirow{2}{*}{$\begin{array}{l}\text { Wearing } \\
\text { Apparel }\end{array}$} & 1990 & $\begin{array}{c}1.33 \\
(3.62)\end{array}$ & $\begin{array}{c}0.83 \\
(2.47)\end{array}$ & $\begin{array}{c}73.1 \\
(155.8)\end{array}$ & $\begin{array}{c}0.21 \\
(0.32)\end{array}$ & $\begin{array}{l}0.28 \\
(0.26)\end{array}$ & $\begin{array}{c}0.21 \\
(0.18)\end{array}$ \\
\hline & 1996 & $\begin{array}{c}2.63 \\
(13.90)\end{array}$ & $\begin{array}{c}1.48 \\
(7.82)\end{array}$ & $\begin{array}{c}62.8 \\
(190.6)\end{array}$ & $\begin{array}{c}0.09 \\
(0.19)\end{array}$ & $\begin{array}{c}0.29 \\
(0.24)\end{array}$ & $\begin{array}{c}0.21 \\
(0.21)\end{array}$ \\
\hline \multirow{2}{*}{$\begin{array}{l}\text { Plastic } \\
\text { Products }\end{array}$} & 1990 & $\begin{array}{c}2.76 \\
(5.50)\end{array}$ & $\begin{array}{c}1.71 \\
(3.86)\end{array}$ & $\begin{array}{c}73.6 \\
(81.3)\end{array}$ & $\begin{array}{c}0.05 \\
(0.10)\end{array}$ & $\begin{array}{c}0.35 \\
(0.23)\end{array}$ & $\begin{array}{c}0.23 \\
(0.22)\end{array}$ \\
\hline & 1996 & $\begin{array}{c}6.87 \\
(14.11)\end{array}$ & $\begin{array}{c}4.03 \\
(9.00)\end{array}$ & $\begin{array}{c}69.2 \\
(84.5)\end{array}$ & $\begin{array}{c}0.08 \\
(0.12)\end{array}$ & $\begin{array}{c}0.42 \\
(0.26)\end{array}$ & $\begin{array}{c}0.23 \\
(0.40)\end{array}$ \\
\hline \multirow{2}{*}{$\begin{array}{l}\text { Food } \\
\text { Products }\end{array}$} & 1990 & $\begin{array}{c}6.91 \\
(13.11)\end{array}$ & $\begin{array}{c}4.60 \\
(9.07)\end{array}$ & $\begin{array}{c}128.9 \\
(172.6)\end{array}$ & $\begin{array}{c}0.58 \\
(0.33)\end{array}$ & $\begin{array}{c}0.11 \\
(0.12)\end{array}$ & $\begin{array}{c}0.18 \\
(0.23)\end{array}$ \\
\hline & 1996 & $\begin{array}{c}9.37 \\
(18.52)\end{array}$ & $\begin{array}{c}5.86 \\
(11.32)\end{array}$ & $\begin{array}{c}135.0 \\
(178.7)\end{array}$ & $\begin{array}{c}0.51 \\
(0.31)\end{array}$ & $\begin{array}{c}0.17 \\
(0.18)\end{array}$ & $\begin{array}{c}0.20 \\
(0.21)\end{array}$ \\
\hline \multirow[t]{2}{*}{ Textiles } & 1990 & $\begin{array}{c}2.21 \\
(4.95)\end{array}$ & $\begin{array}{l}1.23 \\
(2.56)\end{array}$ & $\begin{array}{c}87.4 \\
(185.2)\end{array}$ & $\begin{array}{c}0.11 \\
(0.19)\end{array}$ & $\begin{array}{c}0.37 \\
(0.26)\end{array}$ & $\begin{array}{c}0.23 \\
(0.25)\end{array}$ \\
\hline & 1996 & $\begin{array}{c}2.40 \\
(4.76)\end{array}$ & $\begin{array}{l}1.39 \\
(2.79)\end{array}$ & $\begin{array}{c}69.4 \\
(126.6)\end{array}$ & $\begin{array}{c}0.14 \\
(0.21)\end{array}$ & $\begin{array}{c}0.36 \\
(0.23)\end{array}$ & $\begin{array}{c}0.23 \\
(0.20)\end{array}$ \\
\hline \multirow{2}{*}{$\begin{array}{l}\text { Wood } \\
\text { Products }\end{array}$} & 1990 & $\begin{array}{c}2.21 \\
(5.26)\end{array}$ & $\begin{array}{l}1.39 \\
(3.54)\end{array}$ & $\begin{array}{c}80.0 \\
(136.7)\end{array}$ & $\begin{array}{c}0.35 \\
(0.28)\end{array}$ & $\begin{array}{c}0.20 \\
(0.28)\end{array}$ & $\begin{array}{l}0.20 \\
(0.25)\end{array}$ \\
\hline & 1996 & $\begin{array}{c}3.21 \\
(9.51)\end{array}$ & $\begin{array}{c}1.84 \\
(4.72)\end{array}$ & $\begin{array}{c}71.6 \\
(101.1)\end{array}$ & $\begin{array}{c}0.37 \\
(0.29)\end{array}$ & $\begin{array}{c}0.20 \\
(0.33)\end{array}$ & $\begin{array}{c}0.17 \\
(0.38)\end{array}$ \\
\hline \multirow{2}{*}{$\begin{array}{l}\text { Fabricated } \\
\text { Metals }\end{array}$} & 1990 & $\begin{array}{l}2.62 \\
(6.30)\end{array}$ & $\begin{array}{l}1.53 \\
(3.80)\end{array}$ & $\begin{array}{l}74.0 \\
(99.7)\end{array}$ & $\begin{array}{c}0.11 \\
(0.17)\end{array}$ & $\begin{array}{c}0.36 \\
(0.27)\end{array}$ & $\begin{array}{c}0.26 \\
(0.17)\end{array}$ \\
\hline & 1996 & $\begin{array}{c}3.33 \\
(7.80)\end{array}$ & $\begin{array}{c}1.91 \\
(4.95)\end{array}$ & $\begin{array}{c}63.1 \\
(81.9)\end{array}$ & $\begin{array}{c}0.10 \\
(0.15)\end{array}$ & $\begin{array}{c}0.30 \\
(0.25)\end{array}$ & $\begin{array}{c}0.26 \\
(0.19)\end{array}$ \\
\hline
\end{tabular}

Notes: Table entries are sample means with standard deviations in parentheses. (a) In units of billions of US dollars in 1990. (b) Computed using the sample of exporting (importing) plants for export (import) intensity . Export intensity is the ratio of export sales to total sales. Import intensity is the ratio of real expenditure on imported inputs to real expenditure on total inputs. (c) Computed as (revenue - variable cost)/revenue.

turnovers in the industries in our study. Having a number of entrants and exiting plants in the sample is important for identifying parameters in our model which affect the decision to exit and the distribution of productivity across plants.

Although firms change their trade status, this status is generally persistent as demonstrated in Table 4. The observed persistence suggests the possibility of sunk cost for exporting and importing, which we include in our model below. ${ }^{6}$

We end this section by examining relationships between measures of plants' performance and their export and import status. ${ }^{7}$ While differences in a variety of plant attributes between exporters and non-exporters are well-known (e.g. Bernard and Jensen, 1999), few empirical studies have discussed how plant performance depends on import status. Table 5 presents

\footnotetext{
${ }^{6}$ In our robustness exercises presented in the appendix, we evaluate a model without sunk costs and find that such a model generates much less persistence in trade status.

${ }^{7}$ Differences in a variety of plant attributes between exporters and non-exporters are well-known (e.g. Bernard and Jensen, 1999; Bernard, Eaton, Jensen, and Kortum, 2003). Kasahara and Rodrigue (2008), Ferenandes (2007), and Muendler (2004) discuss how plant performance depends on import status.
} 
Table 3: Number of Changes in Export/Import Status and Entry and Exit

\begin{tabular}{|c|c|c|c|c|c|c|c|c|c|}
\hline & \multicolumn{3}{|c|}{ Wearing Apparel } & \multicolumn{3}{|c|}{ Plastic Products } & \multicolumn{3}{|c|}{ Food Products } \\
\hline & Exp or Imp & Exp & $\operatorname{Imp}$ & Exp or Imp & Exp & Imp & Exp or Imp & Exp & Imp \\
\hline No. of Changes $\geq 1$ & 141 & 65 & 108 & 158 & 80 & 122 & 312 & 136 & 209 \\
\hline No. of Changes $\geq 2$ & 81 & 33 & 50 & 87 & 35 & 59 & 174 & 60 & 116 \\
\hline No. of Changes $\geq 3$ & 31 & 6 & 15 & 42 & 11 & 21 & 65 & 22 & 39 \\
\hline Avg. No. of Entrants per Year & \multirow{2}{*}{\multicolumn{3}{|c|}{$\begin{array}{l}37 \\
30\end{array}$}} & \multicolumn{3}{|c|}{30} & \multirow{2}{*}{\multicolumn{3}{|c|}{53}} \\
\hline \multirow[t]{3}{*}{ Avg. No. of Exiters per Year } & & & & & & & & & \\
\hline & \multicolumn{3}{|c|}{ Textiles } & \multicolumn{3}{|c|}{ Wood Products } & \multicolumn{3}{|c|}{ Fabricated Metals } \\
\hline & Exp or Imp & Exp & $\operatorname{Imp}$ & Exp or Imp & Exp & $\operatorname{Imp}$ & Exp or Imp & Exp & $\operatorname{Imp}$ \\
\hline No. of Changes $\geq 1$ & 207 & 104 & 152 & 106 & 82 & 41 & 170 & 87 & 132 \\
\hline No. of Changes $\geq 2$ & 113 & 50 & 68 & 53 & 37 & 20 & 106 & 34 & 73 \\
\hline No. of Changes $\geq 3$ & 54 & 20 & 22 & 25 & 13 & 7 & 40 & 11 & 22 \\
\hline Avg. No. of Entrants per Year & \multicolumn{3}{|c|}{27} & \multicolumn{3}{|c|}{39} & \multicolumn{3}{|c|}{48} \\
\hline Avg. No. of Exiters per Year & \multicolumn{3}{|c|}{29} & \multicolumn{3}{|c|}{30} & \multicolumn{3}{|c|}{25} \\
\hline
\end{tabular}

estimated premia in various performance measures for each industry according to export and import status. Following Bernard and Jensen (1999), this table reports export and import premia estimated from a pooled ordinary least squares regression using data from 1990-1996 for each industry separately:

$$
\ln X_{i t}=\alpha_{0}+\alpha_{1} d_{i t}^{x}\left(1-d_{i t}^{m}\right)+\alpha_{2} d_{i t}^{m}\left(1-d_{i t}^{x}\right)+\alpha_{3} d_{i t}^{x} d_{i t}^{m}+Z_{i t} \beta+\epsilon_{i t},
$$

where $X_{i t}$ is a vector of plant attributes (employment, sales, labor productivity, wage, nonproduction worker ratio, and capital per worker). Here, $d_{i t}^{x}$ is a dummy for year $t$ 's export status, $d_{i t}^{m}$ is a dummy for year $t$ 's import status, $Z$ includes industry dummies, year dummies, and total employment to control for size. The export premium, $\alpha_{1}$, is the average percentage difference between exporters and non-exporters among plants that do not import foreign intermediates. The import premium, $\alpha_{2}$, is the average percentage difference between importers and nonimporters among plants that do not export. Finally, $\alpha_{3}$ captures the percentage difference between plants that neither export nor import and plants that do both.

The results in Table 5 show that there are substantial differences not only between exporters and non-exporters but also between importers and non-importers. The export premia among non-importers are positive and significant for all characteristics as shown in column 1 for each industry. The import premia among non-exporters are also positive and significant, suggesting the importance of import status in explaining plant performance even after controlling for export status. Comparing columns 1-2 with column 3 for each industry, we note that plants that are both exporting and importing tend to be larger and have higher value added per worker than 
Table 4: Transition Probabilities and Distributions of Export and Import Status

\begin{tabular}{|c|c|c|c|c|c|c|c|c|}
\hline & \multicolumn{4}{|c|}{ Wearing Apparel } & \multicolumn{4}{|c|}{ Plastic Products } \\
\hline & $\begin{array}{l}\text { No Exp/ } \\
\text { No Imp }\end{array}$ & $\begin{array}{c}\text { Exp/ } \\
\text { No Imp }\end{array}$ & $\begin{array}{l}\text { No Exp/ } \\
\text { Imp }\end{array}$ & $\begin{array}{l}\text { Exp/ } \\
\text { Imp }\end{array}$ & $\begin{array}{c}\text { No Exp/ } \\
\text { No Imp }\end{array}$ & $\begin{array}{c}\text { Exp/ } \\
\text { No Imp }\end{array}$ & $\begin{array}{c}\text { No Exp/ } \\
\text { Imp }\end{array}$ & $\begin{array}{l}\text { Exp/ } \\
\text { Imp }\end{array}$ \\
\hline No Exp/No Imp & 0.911 & 0.025 & 0.060 & 0.004 & 0.845 & 0.029 & 0.108 & 0.018 \\
\hline Exp/No Imp & 0.255 & 0.553 & 0.032 & 0.160 & 0.162 & 0.412 & 0.118 & 0.309 \\
\hline No $\operatorname{Exp} / \operatorname{Imp}$ & 0.244 & 0.015 & 0.676 & 0.065 & 0.193 & 0.021 & 0.661 & 0.125 \\
\hline $\operatorname{Exp} / \operatorname{Imp}$ & 0.028 & 0.063 & 0.113 & 0.796 & 0.030 & 0.068 & 0.091 & 0.810 \\
\hline Entrants Dist. & 0.794 & 0.049 & 0.081 & 0.076 & 0.626 & 0.050 & 0.268 & 0.056 \\
\hline \multirow[t]{3}{*}{ Steady State Dist. } & 0.742 & 0.048 & 0.137 & 0.073 & 0.532 & 0.049 & 0.234 & 0.184 \\
\hline & \multicolumn{4}{|c|}{ Food Products } & \multicolumn{4}{|c|}{ Textiles } \\
\hline & $\begin{array}{l}\text { No Exp/ } \\
\text { No Imp }\end{array}$ & $\begin{array}{c}\text { Exp/ } \\
\text { No Imp }\end{array}$ & $\begin{array}{l}\text { No Exp/ } \\
\text { Imp }\end{array}$ & $\begin{array}{l}\text { Exp/ } \\
\text { Imp }\end{array}$ & $\begin{array}{c}\text { No Exp/ } \\
\text { No Imp }\end{array}$ & $\begin{array}{c}\text { Exp/ } \\
\text { No Imp }\end{array}$ & $\begin{array}{l}\text { No Exp/ } \\
\text { Imp }\end{array}$ & $\begin{array}{l}\text { Exp/ } \\
\text { Imp }\end{array}$ \\
\hline No $\operatorname{Exp} /$ No Imp & 0.876 & 0.056 & 0.062 & 0.006 & 0.857 & 0.043 & 0.090 & 0.010 \\
\hline Exp/No Imp & 0.091 & 0.784 & 0.002 & 0.123 & 0.277 & 0.532 & 0.014 & 0.177 \\
\hline No $\operatorname{Exp} / \operatorname{Imp}$ & 0.189 & 0.014 & 0.732 & 0.066 & 0.166 & 0.020 & 0.723 & 0.092 \\
\hline Exp/Imp & 0.009 & 0.206 & 0.038 & 0.746 & 0.024 & 0.065 & 0.061 & 0.850 \\
\hline Entrants Dist. & 0.794 & 0.049 & 0.081 & 0.076 & 0.762 & 0.044 & 0.163 & 0.031 \\
\hline \multirow[t]{3}{*}{ Steady State Dist. } & 0.742 & 0.048 & 0.137 & 0.073 & 0.602 & 0.064 & 0.200 & 0.133 \\
\hline & \multicolumn{4}{|c|}{ Wood Products } & \multicolumn{4}{|c|}{ Fabricated Metals } \\
\hline & $\begin{array}{l}\text { No Exp/ } \\
\text { No Imp }\end{array}$ & $\begin{array}{c}\text { Exp/ } \\
\text { No Imp }\end{array}$ & $\begin{array}{l}\text { No Exp/ } \\
\text { Imp }\end{array}$ & $\begin{array}{l}\text { Exp/ } \\
\text { Imp }\end{array}$ & $\begin{array}{c}\text { No Exp/ } \\
\text { No Imp }\end{array}$ & $\begin{array}{c}\text { Exp/ } \\
\text { No Imp }\end{array}$ & $\begin{array}{l}\text { No Exp/ } \\
\text { Imp }\end{array}$ & $\begin{array}{l}\text { Exp/ } \\
\text { Imp }\end{array}$ \\
\hline No Exp/No Imp & 0.951 & 0.038 & 0.007 & 0.004 & 0.916 & 0.021 & 0.055 & 0.008 \\
\hline Exp/No Imp & 0.159 & 0.775 & 0.003 & 0.064 & 0.274 & 0.415 & 0.019 & 0.292 \\
\hline No $\operatorname{Exp} / \operatorname{Imp}$ & 0.295 & 0.023 & 0.545 & 0.136 & 0.185 & 0.014 & 0.721 & 0.080 \\
\hline Exp/Imp & 0.029 & 0.184 & 0.096 & 0.692 & 0.037 & 0.112 & 0.093 & 0.758 \\
\hline Entrants Dist. & 0.785 & 0.167 & 0.013 & 0.034 & 0.849 & 0.028 & 0.098 & 0.025 \\
\hline Incumbents Dist. & 0.767 & 0.166 & 0.021 & 0.047 & 0.725 & 0.041 & 0.145 & 0.088 \\
\hline
\end{tabular}

Notes: The first four rows for each industry are the probabilities of moving from the trade status listed in the row to the trade status listed in the column in the next period.

plants that are engaged in either exporting or importing but not both. ${ }^{8}$

These results motivate us to develop and estimate a model in the next two sections which incorporates exporting, importing, and differences across plants with respect to productivity and other characteristics. We use the model to further explore the relationships suggested here between plant productivity and export and import status.

\section{$3 \quad$ A Model of Exports and Imports}

Motivated by the empirical evidence presented above, we now extend the trading environment studied by Melitz (2003) to include importing of intermediates by heterogeneous final goods producers. We develop this model to provide a framework for estimating the effects of trade in final goods and trade in intermediates on productivity, welfare, etc. using the data discussed in the previous section.

\footnotetext{
${ }^{8}$ Since export status is positively correlated with import status, the magnitude of the export premia estimated without controlling for import status is likely to be overestimated by capturing the import premia.
} 
Table 5: Premia of Exporter and Importer: Pooled OLS, 1990-1996

\begin{tabular}{l|ccc|ccc|ccc}
\hline & \multicolumn{3}{|c|}{ Wearing Apparel } & \multicolumn{3}{c|}{ Plastic Products } & \multicolumn{3}{c}{ Food Products } \\
\hline Export/Import Status & Exp & Imp & Exp\&Imp & Exp & Imp & Exp\&Imp & Exp & Imp & Exp\&Imp \\
\hline Total & 0.79 & 0.57 & 1.76 & 0.67 & 0.64 & 1.13 & 0.97 & 0.85 & 1.63 \\
Employment & $0.09)$ & $(0.05)$ & $(0.08)$ & $(0.09)$ & $(0.05)$ & $(0.06)$ & $(0.04)$ & $(0.05)$ & $(0.04)$ \\
\hline Total & 1.27 & 1.16 & 2.42 & 1.08 & 1.08 & 1.90 & 0.91 & 1.94 & 2.46 \\
Sales & $(0.10)$ & $(0.06)$ & $(0.09)$ & $(0.11)$ & $(0.07)$ & $(0.07)$ & $(0.05)$ & $(0.07)$ & $(0.05)$ \\
\hline Value Added & 0.46 & 0.56 & 0.53 & 0.46 & 0.41 & 0.77 & 0.09 & 0.92 & 0.88 \\
per Worker & $0.08)$ & $(0.04)$ & $(0.07)$ & $(0.10)$ & $(0.05)$ & $(0.05)$ & $(0.05)$ & $(0.06)$ & $(0.06)$ \\
\hline \hline No. of Observations & \multicolumn{3}{|c|}{2332} & \multicolumn{3}{c|}{1706} & \multicolumn{3}{c}{4040} \\
\hline & \multicolumn{3}{|c|}{ Textiles } & \multicolumn{3}{c|}{ Wood Products } & \multicolumn{2}{c}{ Fabricated Metals } \\
\hline Export/Import Status & Exp & Imp & Exp\&Imp & Exp & Imp & Exp\&Imp & Exp & Imp & Exp\&Imp \\
\hline Total & 0.78 & 0.44 & 1.56 & 1.05 & 0.39 & 1.76 & 0.62 & 0.59 & 1.38 \\
Employment & $(0.07)$ & $(0.04)$ & $(0.06)$ & $(0.04)$ & $(0.12)$ & $(0.09)$ & $(0.08)$ & $(0.04)$ & $(0.06)$ \\
\hline Total & 1.22 & 1.16 & 2.24 & 1.35 & 0.92 & 2.95 & 0.95 & 1.31 & 2.28 \\
Sales & $(0.09)$ & $(0.05)$ & $(0.07)$ & $(0.07)$ & $(0.16)$ & $(0.11)$ & $(0.12)$ & $(0.06)$ & $(0.05)$ \\
\hline Value Added & 0.48 & 0.67 & 0.60 & 0.22 & 0.76 & 0.83 & 0.30 & 0.53 \\
per Worker & $(0.07)$ & $(0.04)$ & $(0.05)$ & $(0.06)$ & $(0.07)$ & $(0.10)$ & $(0.07)$ & $(0.04)$ & $(0.05)$ \\
\hline \hline No. of Observations & \multicolumn{3}{|c|}{2604} \\
\hline
\end{tabular}

Notes: Standard errors are in parentheses. "Total Employment" reports the estimates for exporter/importer premia from a regression excluding the logarithm of total employment from the set of regressors.

\subsection{Environment}

The world is comprised of $N+1$ identical countries. Within each country, there is a set of final goods producers and a set of intermediate goods producers. The final goods sector is our primary focus and is characterized by a continuum of monopolistically competitive firms producing horizontally differentiated goods using labor and intermediate goods. We index firms in this sector by $i$ and let the (endogenous) measure of final goods producers in each country be denoted by $M$.

There is an unbounded measure of ex ante identical potential entrants into this sector. Upon entering, an entrant pays a fixed entry cost, $f_{e}$. Each new entrant then draws a firmspecific productivity parameter, $\varphi_{i}$, a transport cost of exporting its output, $\tau_{i}^{x}$, and a transport cost of importing intermediate inputs, $\tau_{i}^{m}$. Thus, firm $i^{\prime} s$ "type" is characterized by a vector $\eta_{i} \equiv\left(\varphi_{i}, \tau_{i}^{x}, \tau_{i}^{m}\right)$ and this type is fixed throughout the lifetime of the firm. We denote the density function of $\eta$ by $g_{\eta}(\eta)$ and impose restrictions on this distribution below. Firm heterogeneity with respect to productivity is consistent with Melitz (2003) and allows firms to differ with respect to exit decisions and import and export status. The inclusion of heterogeneous international transport costs is motivated by observed differences in export and import status and intensities across plants in the data as presented in the previous section.

At the beginning of period $t$, both entrants and incumbents draw idiosyncratic shocks, $\left(\epsilon_{i t}^{\chi}(0), \epsilon_{i t}^{\chi}(1)\right) \equiv \epsilon_{i t}^{\chi}$, which we refer to as exit cost shocks. Here $\epsilon_{i t}^{\chi}(0)$ is the return if the 
firm chooses to exit and $\epsilon_{i t}^{\chi}(1)$ plus the continuation value (specified below) is the return from continuing to produce, where $\epsilon_{i t}^{\chi}(1)$ is interepreted as an idiosyncratic shock to net current operating profit. After observing these shocks, a firm decides whether to exit or to continue to operate. We assume that $\epsilon_{i t}^{\chi}$ is independent of alternatives and is drawn from the extreme-value distribution with scale parameter $\varrho^{\chi}$. Without these shocks, the model predicts that all firms with productivity below a certain level will exit which is inconsistent with the existence of many small firms in our data.

Firms that stay in the market in period $t$ then draw firm-specific shocks associated with international trade. Specifically, firms receive idiosyncratic export/import shocks associated with each export/import status given by $\left(\epsilon_{i t}^{d}(0,0), \epsilon_{i t}^{d}(1,0), \epsilon_{i t}^{d}(0,1), \epsilon_{i t}^{d}(1,1)\right) \equiv \epsilon_{i t}^{d}$. Here $(0,0)$ denotes the decision to neither export output nor import intermediates, $(1,0)$ denotes the decision to export output but not import intermediates, $(0,1)$ denotes the decision to import intermediates but not export output, and $(1,1)$ denotes the decision to do both. Hence, depending on a firm's choice of export/import status, it receives the continuation value associated with that status plus the relevant export/import shock. The export/import shocks are drawn from the extreme-value distribution with scale parameter $\varrho^{d}$. These shocks are incorporated to capture observed changes in firms' trade status over time in the data. Finally, each continuing firm faces the possibility of a large negative shock with probability $\xi$ that forces the firm to exit.

Thus, continuing firms differ with respect to their type, $\eta_{i}$, and their past and current export/import status. Let $d_{i t} \equiv\left(d_{i t}^{x}, d_{i t}^{m}\right) \in\{(0,0),(1,0),(0,1),(1,1)\} \equiv \mathcal{D}$ denote firm $i^{\prime} s$ export/import status at time $t$ where $d_{i t}^{x}$ denotes export status and $d_{i t}^{m}$ denotes import status. New entrants have past export/import status equal to $(0,0)$.

Firms must pay non-stochastic per-period fixed costs of operating as well as per-period fixed and sunk costs of trading, depending on their current and past export/import status. Total fixed and sunk costs in period $t$ for firm $i$ with past export/import status equal to $d_{i t-1}$ and current status equal to $d_{i t}$ is given as follows:

$$
F\left(d_{i t-1}, d_{i t}\right)= \begin{cases}f & \text { for }\left(d_{i t}^{x}, d_{i t}^{m}\right)=(0,0), \\ f+f^{x}+c^{x}\left(1-d_{i t-1}^{x}\right) & \text { for }\left(d_{i t}^{x}, d_{i t}^{m}\right)=(1,0), \\ f+f^{m}+c^{m}\left(1-d_{i t-1}^{m}\right) & \text { for }\left(d_{i t}^{x}, d_{i t}^{m}\right)=(0,1), \\ f+\zeta\left[f^{x}+f^{m}+c^{x}\left(1-d_{i t-1}^{x}\right)+c^{m}\left(1-d_{i t-1}^{m}\right)\right] & \text { for }\left(d_{i t}^{x}, d_{i t}^{m}\right)=(1,1) .\end{cases}
$$

Here $f$ is the per-period cost of operating in the market while $f^{x}$ and $f^{m}$ are non-stochastic per-period fixed costs of exporting and importing, respectively. The parameter $c^{x}$ represents 
the sunk cost of exporting for a non-exporting plant to start exporting while the parameter $c^{m}$ represents the sunk cost of importing. The parameter $\zeta$ captures the degree of fixed and sunk cost complementarity between exporting and importing. The inclusion of sunk costs of exporting and importing is motivated by empirical evidence on the existence of such costs and improves the model's ability to match observed transition patterns for export and import status. ${ }^{9}$

The technology for final good producer $i$ of type $\eta_{i}$ and import status $d_{i t}^{m}$ is given by:

$$
q\left(\eta_{i}, d_{i t}^{m}\right)=\varphi_{i} l_{i t}^{\alpha}\left[\int_{0}^{1} x_{i t}^{o}(j)^{\frac{\gamma-1}{\gamma}} d j+d_{i t}^{m} \int_{0}^{N} x_{i t}(j)^{\frac{\gamma-1}{\gamma}} d j\right]^{\frac{(1-\alpha) \gamma}{\gamma-1}}
$$

where $l_{i t}$ is labor input, $x_{i t}^{o}(j)$ is input of domestically-produced intermediate variety $j, x_{i t}(j)$ is input of imported intermediate variety $j, 0<\alpha<1$ is the labor share, and $\gamma>1$ is the elasticity of substitution between any two intermediate inputs. Note that the measure of intermediates produced within any country is fixed at 1 (this is discussed further below) and a final goods producer which chooses to use imported intermediates, will import from all of its $N$ trading partners.

This production function incorporates increasing returns to variety in intermediate inputs using an approach similar to that used in many applications in macroeconomics, growth, and international economics. ${ }^{10}$ As is well-known, this feature of the production function implies that firms which use a wider variety of intermediates (here, through importing), will have higher total factor productivity. Thus, our environment is consistent with the empirical evidence presented in Section 2 of this paper and in Amiti and Konings (2005), Halpern, Koren, and Szeidl (2006), and Kasahara and Rodrigue (2008) which suggest that the use of foreign intermediate goods is associated with higher plant productivity. ${ }^{11}$

We now turn to the intermediate goods industry where there is a continuum of firms producing differentiated goods. The measure of varieties produced within a country is fixed at one, as noted above. ${ }^{12}$ Anyone can access the blueprints of the intermediate production technology

\footnotetext{
${ }^{9}$ See Roberts and Tybout (1998), Bernard and Jensen (2002), and Das, Roberts, and Tybout (2007) for evidence of sunks cost of exporting and Kasahara and Rodrigue (2008) for sunk costs of importing.

${ }^{10}$ See, for example, Devereux, Head, and Lapham (1996a, 1996b), Ethier (1982), Grossman and Helpman (1991), and Romer (1987).

${ }^{11}$ An alternative approach would be to incorporate vertically differentiated inputs with foreign inputs of higher quality to generate a positive relationship between importing and plant productivity. Halpern, Koren, and Szeidl (2006) use Hungarian plant data and find that approximately two-thirds of the increase in plant productivity due to importing is attributable to an increase in the variety of intermediates used in production while the remaining one-third is due to an increase in quality. For ease of exposition and tractability, we focus on the former effect.

${ }^{12}$ Thus, we are abstracting from the effects of trade on the measure of intermediates produced within a country. Our environment does, however, capture the effects of trade on the measure of varieties of final goods produced
} 
for all varieties and there is free entry. Firms have identical linear technologies in labor input with marginal product equal to one. These conditions imply that domestic intermediates sold in the domestic market will all have price equal to the wage which we normalize to one.

Finally, there is a representative consumer in each country who supplies labour inelastically at level $L$ in each period. The consumer's preferences over consumption of the continuum of final goods available for consumption are given by $U_{t}=\left[\int_{i \in \Omega_{t}} c_{i t}^{\frac{\sigma-1}{\sigma}} d i\right]^{\frac{\sigma}{\sigma-1}}$, where $\Omega_{t}$ is the set of final goods available to the consumer, and $\sigma>1$ is the elasticity of substitution between varieties. Letting $p_{i t}$ denote the price of variety $i$, we can derive optimal consumption of variety $i$ to be $c_{i t}=C_{t}\left[\frac{p_{i t}}{P_{t}}\right]^{-\sigma}$, where $P_{t}$ is a price index given by $P_{t}=\left[\int_{i \in \Omega_{t}} p_{i t}^{1-\sigma} d i\right]^{1 /(1-\sigma)}$ and $C_{t}$ is a consumption index with $C_{t}=U_{t}$. Expenditure on variety $i \in \Omega_{t}$ is given by

$$
r_{i t}=R_{t}\left[\frac{p_{i t}}{P_{t}}\right]^{1-\sigma}
$$

where $R_{t}=P_{t} C_{t}=\int_{i \in \Omega_{t}} r_{i t} d i$ is aggregate expenditure.

\subsection{Production and Pricing Decisions}

We begin by examining the end-of-period static production and pricing decision of final good producer $i$ with $\eta_{i} \equiv\left(\varphi_{i}, \tau_{i}^{x}, \tau_{i}^{m}\right)$ and export/import status $d_{i t}$. The dynamic decisions of exit and whether or not to export output and import intermediates are explored below. In the symmetric equilibrium in period $t$, a final goods producer will employ the same quantity of each domestic intermediate: $x_{i t}^{o}(j)=x_{i t}^{o}$ for all $j$. If the firm is using imported intermediates at time $t$, the firm must purchase $\tau_{i}^{m}>1$ units of an intermediate good for one unit of the intermediate to arrive for use in production. Thus, cost minimization implies that when a firm uses imported intermediates, the input of any imported variety will equal $x_{i t}(j)=x_{i t}=\left(\tau_{i}^{m}\right)^{-\gamma} x_{i t}^{o}$ for all $j$. Hence, total expenditure on intermediate inputs by firm $i$ equals

$$
x_{i t}^{o}+d_{i t}^{m} N \tau_{i}^{m} x_{i t}=\left(1+d_{i t}^{m} N \tau_{i}^{m 1-\gamma}\right) x_{i t}^{o} .
$$

We can derive output for such a firm from (3) as

$$
q\left(\eta_{i}, d_{i t}^{m}\right)=a\left(\eta_{i}, d_{i t}^{m}\right) l_{i t}^{\alpha}\left[\left(1+d_{i t}^{m} N \tau_{i}^{m}\right) x_{i t}^{o}\right]^{1-\alpha},
$$

within a country and on the measure of varieties of final goods available to consumers in a country. We take this approach so as to focus on the effects of trade on the final good sector and to provide estimation of the baseline model of Melitz (2003). Incorporating an endogenous measure of intermediate varieties is an interesting avenue for future work but is beyond the scope of this paper. 
where

$$
a\left(\eta_{i}, d_{i t}^{m}\right) \equiv \varphi_{i} \lambda_{i}^{d_{i t}^{m}}
$$

with $\lambda_{i} \equiv\left(1+N \tau_{i}^{m 1-\gamma}\right)^{\frac{1-\alpha}{\gamma-1}}>1$. We will refer to $a\left(\eta_{i}, d_{i t}^{m}\right)$ as firm i's total factor productivity. ${ }^{13}$ Note that $a\left(\eta_{i}, 1\right)>a\left(\eta_{i}, 0\right)$ so, as discussed above, a firm which imports intermediates will have higher total factor productivity than if it does not import because of the increasing returns to variety.

The form of preferences implies that final goods producers will price at a constant markup equal to $\frac{\sigma}{\sigma-1}$ over marginal cost. Hence, using the final goods technology and recalling that all intermediates are priced at the wage which equals one, we have the following pricing rule in period $t$ for final goods sold in the domestic market by a domestic producer $i$ :

$$
p_{i t}^{h}=\left(\frac{\sigma}{\sigma-1}\right)\left(\frac{1}{\Gamma a\left(\eta_{i}, d_{i t}^{m}\right)}\right)
$$

where $\Gamma \equiv \alpha^{\alpha}(1-\alpha)^{1-\alpha}$. Recalling that firms face firm-specific iceberg transport costs for exporting their output equal to $\tau_{i}^{x}>1$, we have the following pricing rule for final goods sold in foreign markets by domestic producer $i: p_{i t}^{f}=\tau_{i}^{x} p_{i t}^{h}$.

Using (4) and (8), we can derive revenue from domestic sales for domestic final goods producer $i$ :

$$
r_{i t}^{h}=R_{t}\left[\left(\frac{\sigma-1}{\sigma}\right) \Gamma P_{t} a\left(\eta_{i}, d_{i t}^{m}\right)\right]^{\sigma-1} .
$$

Revenue from foreign sales for final good producer $i$ with export/import status equal to $d_{i t} \equiv$ $\left(d_{i t}^{x}, d_{i t}^{m}\right)$ equals

$$
r_{i t}^{f}=d_{i t}^{x} N \tau_{i}^{x 1-\sigma} r_{i t}^{h}
$$

Hence, total revenue for domestic firm $i$ is given by

$$
r_{i t} \equiv r_{i t}^{h}+r_{i t}^{f}=\left(1+d_{i t}^{x} N \tau_{i}^{x 1-\sigma}\right) r_{i t}^{h}
$$

Finally, profits, net of shocks, for domestic firm $i$ are given by

$$
\pi\left(\eta_{i}, d_{i t-1}, d_{i t}\right)=\frac{r_{i t}}{\sigma}-F\left(d_{i t-1}, d_{i t}\right)
$$

where non-stochastic fixed and sunk costs, $F\left(d_{i t-1}, d_{i t}\right)$, are given in equation (2).

\footnotetext{
${ }^{13}$ Note that $l_{i t}$ is the firm's labour input and $x_{i t}^{o}+d_{i t}^{m} N \tau_{i}^{m} x_{i t}$ is a firm's gross input of intermediate inputs so $a\left(\eta_{i}, d_{i t}^{m}\right)$ is a residual measure of productivity.
} 


\subsection{Exit, Exporting, and Importing Decisions}

We now turn to the dynamic component of a final good producer's optimization problem. The Bellman equations which characterize the optimization problem for final good producer $i$ with $\left(\eta_{i}, d_{i t-1}, \epsilon_{i t}^{\chi}, \epsilon_{i t}^{d}\right)$ are written as follows:

$$
\begin{aligned}
V\left(\eta_{i}, d_{i t-1}, \epsilon_{i t}^{\chi}\right) & =\max \left\{\epsilon_{i t}^{\chi}(0), \epsilon_{i t}^{\chi}(1)+\int W\left(\eta_{i}, d_{i t-1}, \epsilon^{d}\right) d H^{d}\left(\epsilon^{d}\right)\right\} \\
W\left(\eta_{i}, d_{i t-1}, \epsilon_{i t}^{d}\right) & =\max _{d^{\prime} \in \mathcal{D}}\left(\epsilon^{d}\left(d^{\prime}\right)+\pi\left(\eta_{i}, d_{i t-1}, d^{\prime}\right)+\beta(1-\xi) \int V\left(\eta_{i}, d^{\prime}, \epsilon^{\chi}\right) d H^{\chi}\left(\epsilon^{\chi}\right)\right)
\end{aligned}
$$

where $H^{\chi}$ and $H^{d}$ represent the cumulative distribution functions of $\epsilon^{\chi}$ and $\epsilon^{d}$, respectively, $\beta \in(0,1)$ is the discount factor, and $\mathcal{D} \equiv\{(0,0),(1,0),(0,1),(1,1)\}$ is the choice set for export/import status. ${ }^{14}$ Now $V(\cdot, \cdot, \cdot)$ represents the value of a firm at the beginning of the period and equation (13) characterizes the decision to exit or remain after observing the exit cost shock. Namely, a firm exits if the value of $\epsilon_{i t}^{\chi}(0)$ is larger than the value of $\epsilon_{i t}^{\chi}(1)+$ $\int W\left(\eta_{i}, d_{i t-1}, \epsilon^{d}\right) d H^{d}\left(\epsilon^{d}\right)$, where $\int W\left(\eta_{i}, d_{i t-1}, \epsilon^{d}\right) d H^{d}\left(\epsilon^{d}\right)$ is the expected continuation value for a firm that chooses to stay with state variable $\left(\eta_{i}, d_{i t-1}\right)$. Equation (14) characterizes the firm's export and import decision after observing export/import cost shocks and recursively defines the value of a firm with state variable $\left(\eta_{i}, d_{i t-1}\right)$ and cost shock $\epsilon_{i t}^{d}$.

In what follows, it is useful to define expected value functions as:

$$
\begin{aligned}
\bar{V}\left(\eta_{i}, d_{i t-1}\right) & =\int V\left(\eta_{i}, d_{i t-1}, \epsilon^{\chi}\right) d H^{\chi}\left(\epsilon^{\chi}\right), \\
\bar{W}\left(\eta_{i}, d_{i t-1}\right) & =\int W\left(\eta_{i}, d_{i t-1}, \epsilon^{d}\right) d H^{d}\left(\epsilon^{d}\right) .
\end{aligned}
$$

\subsection{Equilibria}

We focus on stationary equilibria in which aggregate variables remain constant over time. In particular, the aggregate price index, $P$, aggregate revenue, $R$, the measure of final goods producers, and the distribution of those producers by type and by export/import status is constant. We denote the stationary equilibrium distribution of these variables across operating firms by $\mu^{*}(\eta, d)$. Of course, individual firms enter, exit, and change their export/import status over time as they receive the idiosyncratic shocks described above. We drop the time subscript and denote the state for final goods producer $i$ as $\left(\eta_{i}, d_{i}\right)$.

In the stationary equilibrium, free entry into final goods production implies that the expected

\footnotetext{
${ }^{14}$ Recall that for entrants in period $t$, we have $d_{t-1}=(0,0)$.
} 
value of an entering firm must equal the fixed entry cost:

$$
\int \bar{V}(\eta,(0,0)) g_{\eta}(\eta) d \eta=f_{e}
$$

Stationarity also requires that the number of firms which exit equals the number of successful entrants:

$$
M \int\left(\sum_{d \in \mathcal{D}} P^{\chi}(0 \mid \eta, d) \mu^{*}(\eta, d)\right) g_{\eta}(\eta) d \eta=M_{e} \int\left(P^{\chi}(1 \mid \eta,(0,0))\right) g_{\eta}(\eta) d \eta
$$

where $M$ is the mass of incumbents, $M_{e}$ is the mass of firms that attempt to enter, $P^{\chi}(0 \mid \eta, d)$ is the probability of exit for a firm with state $(\eta, d)$ and $P^{\chi}(1 \mid \eta, d)=1-P^{\chi}(0 \mid \eta, d)$ is the probability of not exiting for such a firm. Now, using the properties of extreme-value distributed random variables (see, for example, Ben-Akiva and Lerman, 1985), we can derive the latter probability as:

$$
P^{\chi}(1 \mid \eta, d)=(1-\xi)\left(\frac{\exp \left(\bar{W}(\eta, d) / \varrho^{\chi}\right)}{\exp (0)+\exp \left(\bar{W}(\eta, d) / \varrho^{\chi}\right)}\right)
$$

where $\bar{W}(\cdot, \cdot)$ is defined in equation $(16)$.

The final condition that the stationary equilibrium must satisfy is that the measure of firms with state $(\eta, d)$ is constant. To write that condition, we first derive the choice probabilities for all possible current export/import statuses conditional on continuing to operate and the firm's state, $(\eta, d)$. These follow the familiar logit formula (see, for example, McFadden, 1978) and are as follows:

$$
P^{d}\left(d^{\prime} \mid \eta, d\right)=\frac{\exp \left(\left[\pi\left(\eta, d, d^{\prime}\right)+\beta(1-\xi) \bar{V}\left(\eta, d^{\prime}\right)\right] / \varrho^{d}\right)}{\sum_{\tilde{d} \in \mathcal{D}} \exp \left([\pi(\eta, d, \tilde{d})+\beta(1-\xi) \bar{V}(\eta, \tilde{d})] / \varrho^{d}\right)}
$$

for $d^{\prime} \in \mathcal{D}$. Hence, the equilibrium condition is written

$$
M \mu^{*}(\eta, d)=M \sum_{d^{\prime} \in \mathcal{D}} P^{d}\left(d \mid \eta, d^{\prime}\right) P^{\chi}\left(1 \mid \eta, d^{\prime}\right) \mu^{*}\left(\eta, d^{\prime}\right)+M_{e} P^{d}(d \mid \eta,(0,0)) P^{\chi}(1 \mid \eta,(0,0)) g_{\eta}(\eta)
$$

for all states $(\eta, d)$. The first term on the right-hand side is the measure of survivors from last period with state $(\eta, d)$ while the second term represents the measure of new entrants with that state. 


\section{Structural Estimation}

We now turn to the development and estimation of an empirical model based on the above model. We use the estimated model to quantify, among other things, the effects of restrictions on trade on productivity and welfare.

\subsection{Empirical Methodology}

We begin by placing distributional assumptions on the parameters which determine plant $i^{\prime} s$ type, $\eta_{i}=\left(\varphi_{i}, \tau_{i}^{x}, \tau_{i}^{m}\right)$. Let $(\sigma-1) \ln \left(\varphi_{i}\right)$ be drawn upon entry from $N\left(0,\left(\sigma^{\varphi}\right)^{2}\right)$. For the plant-specific transportation costs, we define the following variables for notational convenience:

$$
z_{i}^{x} \equiv N \tau_{i}^{x 1-\sigma} \quad z_{i}^{m} \equiv N \tau_{i}^{m 1-\gamma}
$$

We assume that, conditional on $\varphi_{i}$, that $z_{i}^{x}$ and $z_{i}^{m}$ are independent of each other and are drawn at the time of entry from log normal distributions with means $\mu^{x}$ and $\mu^{m}$ and standard deviations $\sigma^{x}$ and $\sigma^{m}$, respectively. Henceforth, we let plant $i^{\prime} s$ type be designated by $\tilde{\eta}_{i} \equiv$ $\left((\sigma-1) \ln \left(\varphi_{i}\right), \ln \left(z_{i}^{x}\right), \ln \left(z_{i}^{m}\right)\right)^{\prime}$.

Now equations (7), (9), (11), and (22) can be used to derive the following expression for total revenue for plant $i$ in period $t$ in the stationary equilibrium of the model:

$$
r_{i t}=\left(1+d_{i t}^{x} z_{i}^{x}\right) R\left[\left(\frac{\sigma-1}{\sigma}\right) \Gamma P \varphi_{i}\left(1+z_{i}^{m}\right)^{\frac{(1-\alpha) d_{i t}^{m}}{\gamma-1}}\right]^{\sigma-1}
$$

We can also use equations (5), (10), and (11) to derive export and import intensities in the stationary equilibrium for plant $i$ at time $t$ if that plant engages in these activities:

$$
\begin{array}{cc}
\kappa_{i t}^{x} \equiv \frac{r_{i t}^{f}}{r_{i t}}=\frac{z_{i}^{x}}{1+z_{i}^{x}} & \text { if } d_{i t}^{x}=1, \\
\kappa_{i t}^{m} \equiv \frac{N \tau_{i}^{m} x_{i t}^{m}}{x_{i t}^{o}+N \tau_{i}^{m} x_{i t}^{m}}=\frac{z_{i}^{m}}{1+z_{i}^{m}} & \text { if } d_{i t}^{m}=1 .
\end{array}
$$

For the estimation, we impose additional assumptions. We assume that plant revenue, $r_{i t}$, export intensity, $\kappa_{i t}^{x}$, and import intensity, $\kappa_{i t}^{m}$ are measured with error. We also allow for labor augmented technological change at an annual rate of $\alpha_{t}$. With these assumptions, we use equations (23) - (25) to specify the logarithm of observed total revenue, export intensity, and 
import intensity for plant $i$ in period $t$ as follows:

$$
\begin{array}{lc}
\ln \left(r_{i t}\right)=\alpha_{0}+\alpha_{t} t+(\sigma-1) \ln \left(\varphi_{i}\right)+\ln \left(1+z_{i}^{x}\right) d_{i t}^{x}+\alpha_{m} \ln \left(1+z_{i}^{m}\right) d_{i t}^{m}+\omega_{i t}^{r}, \\
\ln \left(\kappa_{i t}^{x}\right)=\ln \left(z_{i}^{x} /\left(1+z_{i}^{x}\right)\right)+\omega_{i t}^{x} & \text { if } d_{i t}^{x}=1, \\
\ln \left(\kappa_{i t}^{m}\right)=\ln \left(z_{i}^{m} /\left(1+z_{i}^{m}\right)\right)+\omega_{i t}^{m} & \text { if } d_{i t}^{m}=1,
\end{array}
$$

where $\omega_{i t}^{r}, \omega_{i t}^{x}$, and $\omega_{i t}^{m}$ are measurement errors and

$$
\begin{aligned}
\alpha_{0} & =\ln (R)+(\sigma-1) \ln \left(\left(\frac{\sigma-1}{\sigma}\right) \Gamma P\right), \\
\alpha_{m} & =\frac{(1-\alpha)(\sigma-1)}{\gamma-1} .
\end{aligned}
$$

We also assume that the gross profit margin is measured with error. Thus, using (8), we have

$$
\frac{r_{i t}-v c_{i t}}{r_{i t}}=\frac{1}{\sigma}+\omega_{i t}^{\sigma}
$$

where $v c_{i t}$ is observed variable cost and $\omega_{i t}^{\sigma}$ is measurement error.

In addition, we assume that, conditional on $\left(\tilde{\eta}_{i}, d_{i t}^{x}, d_{i t}^{m}\right), \omega_{i t} \equiv\left(\omega_{i t}^{r}, \omega_{i t}^{x}, \omega_{i t}^{m}, \omega_{i t}^{\sigma}\right)^{\prime}$ is randomly drawn from $N\left(0, \Sigma_{\omega}\right)$ and we denote its probability density function by $g_{\omega}(\cdot)$. We reparametrize $\Sigma_{\omega}$ using the unique lower triangular Cholesky decomposition as $\Sigma_{\omega}=\Lambda_{\omega} \Lambda_{\omega}^{\prime}$ and denote the $(j, k)$-th component of $\Lambda_{\omega}$ by $\lambda_{j, k} \cdot{ }^{15}$

Given these assumptions, we can use equation (12) and the revenue function given in equation (26) to derive profits for plant $i$ at time $t, \pi\left(\tilde{\eta}_{i}, d_{i t-1}, d_{i t}\right)$. We then use these profit functions to construct the Bellman equations for each plant using equations (15)-(16).

Finally, we use maximum likelihood to estimate the following parameter vector $\theta:{ }^{16}$

$$
\theta \equiv\left(\sigma, f, f^{x}, f^{m}, c^{x}, c^{m}, \zeta, \alpha_{0}, \alpha_{t}, \alpha_{m}, \mu^{x}, \mu^{m}, \sigma^{\varphi}, \sigma^{x}, \sigma^{m}, \xi, \varrho^{\chi}, \varrho^{d}, v e c\left(\Lambda_{\omega}\right)^{\prime}, \tilde{\theta}_{0}^{\prime}\right)^{\prime}
$$

where $\operatorname{vec}\left(\Lambda_{\omega}\right)=\left(\lambda_{11}, \lambda_{21}, \lambda_{22}, \lambda_{31}, \lambda_{32}, \lambda_{33}, \lambda_{41}, \lambda_{42}, \lambda_{43}, \lambda_{44}\right)^{\prime}$ is the parameter vector determining the measurement error distribution while the set of parameters that specify the initial distribution in 1990 is given by $\tilde{\theta}_{0}=\left(\mu_{0}^{\varphi}, \mu_{0}^{x}, \mu_{0}^{m}, \sigma_{0}^{\varphi}, \sigma_{0}^{x}, \sigma_{0}^{m}, \alpha_{0}^{x}, \alpha_{1}^{x}, \alpha_{2}^{x}, \alpha_{3}^{x}, \alpha_{0}^{m}, \alpha_{1}^{m}, \alpha_{2}^{m}, \alpha_{3}^{m}\right)^{\prime}$. In

\footnotetext{
${ }^{15}$ We note that the normality assumption is restrictive. In particular, since the measurement error enters in the revenue function (26) in terms of the logarithm, the measurement error in (31) may not be normally distributed. Thus, the normal distribution should be viewed as an approximation to the true underlying joint distribution of measurement errors in order to parsimoniously capture the correlation of measurement errors across equations.

${ }^{16}$ The discount factor $\beta$ is not estimated but is set to 0.95 . It is difficult to identify the discount factor in dynamic discrete choice models (cf., Rust, 1987).
} 
what follows, we briefly describe the estimation methodology we use to estimate $\theta$ and provide full details in the appendix.

Recalling that $\epsilon^{\chi}$ and $\epsilon^{d}$ are type I extreme-value distributed random variables, we can write the Bellman's equations given by (15)-(16) for plant $i$ as follows (see the appendix):

$$
\begin{aligned}
& \bar{V}\left(\tilde{\eta}_{i}, d_{i t-1}\right)=\varrho^{\chi} \ln \left(\exp (0)+\exp \left(\bar{W}\left(\tilde{\eta}_{i}, d_{i t-1}\right) / \varrho^{\chi}\right)\right) \\
& \bar{W}\left(\tilde{\eta}_{i}, d_{i t-1}\right)=\varrho^{d} \ln \left(\sum_{d^{\prime} \in \mathcal{D}} \exp \left(\left[\pi\left(\tilde{\eta}_{i}, d_{i t-1}, d^{\prime}\right)+\beta \exp \left(\alpha_{t}\right)(1-\xi) \bar{V}\left(\tilde{\eta}_{i}, d^{\prime}\right)\right] / \varrho^{d}\right)\right),
\end{aligned}
$$

where we have "detrended" firms' problems by using the trend-adjusted discount factor $\beta \exp \left(\alpha_{t}\right)$ in place of the discount factor $\beta .^{17}$

Given a value for $\theta$, we can solve the approximated model with a finite number of grid points over firms' types, $\tilde{\eta}=\left((\sigma-1) \ln (\varphi), \ln \left(z^{x}\right), \ln \left(z^{m}\right)\right)^{\prime}$. The continuous state space of $(\sigma-1) \ln (\varphi)$ is approximated by $n_{\varphi}$ grid points uniformly distributed between $\underline{\varphi}$ and $\bar{\varphi}$ while the continuous state space of $\ln \left(z^{x}\right)$ and $\ln \left(z^{m}\right)$ is approximated by $n_{z}$ grid points so that $\ln \left(z^{x} /\left(1+z^{x}\right)\right)$ and $\ln \left(z^{m} /\left(1+z^{m}\right)\right)$ are uniformly distributed between 0 and 1 together with two additional end points at 0.0001 and 0.9999 . Thus, the continuous state space of $\tilde{\eta}$ is approximated by $n_{\eta}=n_{\varphi} \times n_{z} \times n_{z}$ points. The distribution function of $\tilde{\eta}$ is accordingly approximated by a multinomial distribution. In practice, we choose $\underline{\varphi}=-5, \bar{\varphi}=5, n_{\varphi}=20$, and $n_{z}=22$.

Let $\tilde{\eta}^{k}$ and $\omega^{k}$ for $k=1, \ldots, n_{\eta}$ be the grid points and weights associated with the multinomial distribution, respectively. Given a $\theta$, we can find the fixed point of the Bellman's equations for each $\tilde{\eta}^{k}$ by iterating on (33)-(34) starting from an initial guess of $W^{o}\left(\tilde{\eta}^{k}, d\right)=0 \forall d \in \mathcal{D}$, until convergence. Once the fixed point is computed, we evaluate the conditional choice probabilities in equations (19)-(54) for each $\tilde{\eta}^{k}$. We denote these probabilities as $P_{\theta}^{\chi}\left(\cdot \mid \tilde{\eta}^{k}, d\right)$ for the exit choice and as $P_{\theta}^{d}\left(\cdot \mid \tilde{\eta}^{k}, d\right)$ for the export/import choice. The stationary distribution, $\mu_{\theta}^{*}(\tilde{\eta}, d)$ is then computed using the conditions for a stationary equilibrium given by equations (18) and (21).

The density of initial draws upon successful entry, $g_{\theta}^{e}(\tilde{\eta})$ is evaluated at $\tilde{\eta}^{k}$ as

$$
g_{\theta}^{e}\left(\tilde{\eta}^{k}\right)=\frac{\omega^{k} P_{\theta}^{\chi}\left(1 \mid \tilde{\eta}^{k},(0,0)\right)}{\sum_{j=1}^{n_{\eta}} \omega^{j} P_{\theta}^{\chi}\left(1 \mid \tilde{\eta}^{j},(0,0)\right)} .
$$

Finally, we need to derive the conditional density function for observed components of $\omega_{i t}$, conditional on $\left(\tilde{\eta}_{i}, d_{i t}\right)$. Conditioning on $\tilde{\eta}_{i}$, we can compute an estimate of $\omega_{i t}, \tilde{\omega}_{i t}\left(\tilde{\eta}_{i}\right)$ using

\footnotetext{
${ }^{17}$ In estimation, we restrict the value of $\beta \exp \left(\alpha_{t}\right)(1-\xi)$ to be no more than 0.99 so that the value function iteration does not diverge.
} 
(23)-(25). We can then derive the following conditional density function:

$$
g_{\omega, \theta}\left(\omega_{i t} \mid \tilde{\eta}_{i}, d_{i t}\right)= \begin{cases}g_{\omega^{r}}\left(\tilde{\omega}_{i t}^{r}\left(\tilde{\eta}_{i}\right)\right) g_{\omega^{\sigma} \mid \omega^{r}}\left(\tilde{\omega}_{i t}^{\sigma}\left(\tilde{\eta}_{i}\right) \mid \tilde{\omega}_{i t}^{r}\left(\tilde{\eta}_{i}\right)\right) & \text { for } d_{i t}=(0,0), \\ g_{\omega^{r}}\left(\tilde{\omega}_{i t}^{r}\left(\tilde{\eta}_{i}\right)\right) g_{\omega^{x} \mid \omega^{r}}\left(\tilde{\omega}_{i t}^{x}\left(\tilde{\eta}_{i}\right) \mid \tilde{\omega}_{i t}^{r}\left(\tilde{\eta}_{i}\right)\right) g_{\omega^{\sigma} \mid \omega^{r}, \omega^{x}}\left(\tilde{\omega}_{i t}^{\sigma}\left(\tilde{\eta}_{i}\right) \mid \tilde{\omega}_{i t}^{r}\left(\tilde{\eta}_{i}\right), \tilde{\omega}_{i t}^{x}\left(\tilde{\eta}_{i}\right)\right) & \text { for } d_{i t}=(1,0) \\ g_{\omega^{r}}\left(\tilde{\omega}_{i t}^{r}\left(\tilde{\eta}_{i}\right)\right) g_{\omega^{m} \mid \omega^{r}}\left(\tilde{\omega}_{i t}^{m}\left(\tilde{\eta}_{i}\right) \mid \tilde{\omega}_{i t}^{r}\left(\tilde{\eta}_{i}\right)\right) g_{\omega^{\sigma} \mid \omega^{r}, \omega^{m}}\left(\tilde{\omega}_{i t}^{\sigma}\left(\tilde{\eta}_{i}\right) \mid \tilde{\omega}_{i t}^{r}\left(\tilde{\eta}_{i}\right), \tilde{\omega}_{i t}^{m}\left(\tilde{\eta}_{i}\right)\right) & \text { for } d_{i t}=(0,1) \\ g_{\omega}\left(\tilde{\omega}_{i t}\left(\tilde{\eta}_{i}\right)\right) & \text { for } d_{i t}=(1,1)\end{cases}
$$

where $g_{\omega^{r}}(\cdot)$ is the marginal distribution of $\omega_{i t}^{r}, g_{\omega^{j} \mid \omega^{r}}\left(\omega_{i t}^{j} \mid \omega_{i t}^{r}\right)$ is the conditional distribution of $\omega_{i t}^{j}$ given $\omega_{i t}^{r}$ for $j \in\{x, m, \sigma\}$, and $g_{\omega^{\sigma} \mid \omega^{r}, \omega^{k}}\left(\omega_{i t}^{\sigma} \mid \omega_{i t}^{r}, \omega_{i t}^{k}\right)$ is the conditional distribution of $\omega_{i t}^{\sigma}$ given $\omega_{i t}^{r}$ and $\omega_{i t}^{k}$ for $k \in\{x, m\}$.

We now discuss the construction of the likelihood function for plant $i$. Let $t_{i o}$ denote the first year in which plant $i$ appears in the data. Conditioning on $\tilde{\eta}_{i}$, the likelihood contribution from the observation for plant $i$ in period $t>t_{i o}$ is computed as:

$$
L_{i t}\left(\theta \mid \tilde{\eta}_{i}, d_{i t-1}\right)= \begin{cases}P_{\theta}^{\chi}\left(0 \mid \tilde{\eta}_{i}, d_{i t-1}\right) & \text { for } \chi_{i t}=0, \\ \underbrace{P_{\theta}^{\chi}\left(1 \mid \tilde{\eta}_{i}, d_{i t-1}\right)}_{\text {Staying }} \underbrace{P_{\theta}^{d}\left(d_{i t} \mid \tilde{\eta}_{i}, d_{i t-1}\right)}_{\text {Export/Import Revenue/Intensity }} \underbrace{g_{\omega, \theta}\left(\omega_{i t} \mid \tilde{\eta}_{i}, d_{i t}\right)} & \text { for } \chi_{i t}=1 .\end{cases}
$$

For the initial period of operation for plant $i, t_{i o}$, the likelihood is given by

$$
L_{i t_{i o}}\left(\theta \mid \tilde{\eta}_{i},(0,0)\right)=P_{\theta}^{d}\left(d_{i t_{i o}} \mid \tilde{\eta}_{i},(0,0)\right) g_{\omega, \theta}\left(\omega_{i t_{i o}} \mid \tilde{\eta}_{i}, d_{i t_{i o}}\right)
$$

With these, we can write the likelihood contribution from plant $i$ conditioned on $\left(\tilde{\eta}_{i}, d_{i t_{i o}}\right)$ as

$$
L_{i}\left(\theta \mid \tilde{\eta}_{i}, d_{i t_{i o}}\right)=\prod_{t=t_{i o}+1}^{T_{i}} L_{i t}\left(\theta \mid \tilde{\eta}_{i}, d_{i t-1}\right)
$$

where $T_{i}$ is the last year in which plant $i$ appears in the data.

To compute the likelihood contribution from plant $i$, we integrate out $\tilde{\eta}$ from the conditional likelihood (49) using appropriate distributions of $\tilde{\eta}$ as implied by the model. In particular, we assume that $\eta$ is drawn from $g_{\theta}^{e}(\tilde{\eta})$ defined in (48) for a plant that enters during the sample period. For a plant observed in the first year of the sample period, 1990, we could assume that $\tilde{\eta}$ is distributed according to the stationary distribution $\mu_{\theta}^{*}(\tilde{\eta}, d)$ defined in $(21)$. In the mid 1980's, however, Chile experienced aggregate shocks, which may have caused deviations from the steady state in 1990 and the stationarity assumption may not be appropriate for the initial 
year. For this reason, we use a "flexible" but parsimonious initial conditions distribution in the spirit of Heckman (1981) to determine the distribution of $\tilde{\eta}$ in 1990 which we denote as $\mu_{0, \theta}(\tilde{\eta}, d)$.

Details of this procedure are given in the appendix.

The likelihood contribution from plant $i$ is determined as:

$$
L_{i}(\theta)= \begin{cases}\sum_{k=1}^{n_{\eta}} L_{i}\left(\theta \mid \tilde{\eta}^{k}, d_{i t_{i o}}\right) \mu_{0, \theta}\left(\tilde{\eta}^{k}, d_{i t_{i o}}\right) & \text { for } t_{i o}=1990 \\ \sum_{k=1}^{n_{\eta}} L_{i}\left(\theta \mid \tilde{\eta}^{k}, d_{i t_{i o}}\right) P_{\theta}^{d}\left(d_{i t_{i o}} \mid \tilde{\eta}^{k},(0,0)\right) g_{\omega, \theta}\left(\omega_{i t_{i o}} \mid \tilde{\eta}^{k}, d_{i t_{i o}}\right) g_{\theta}^{e}\left(\tilde{\eta}^{k}\right) & \text { for } t_{i o}>1990 .\end{cases}
$$

Finally, the parameter vector $\theta$ is estimated by maximizing the following log-likelihood function:

$$
\mathcal{L}(\theta) \equiv \sum_{i=1}^{\mathcal{N}} L_{i}(\theta)
$$

where $\mathcal{N}$ is the number of plants in the data.

In summary, for each candidate parameter vector, $\theta$, we solve the discretized versions of (33)-(34) and then use those solutions to obtain the choice probabilities using (19)-(54), the stationary distribution for $(\tilde{\eta}, d)$, the conditional distributions for $\omega$, and the distribution of $\tilde{\eta}$ upon entry. We then use these to evaluate the log-likelihood function given by (38). We repeat this process to maximize $\mathcal{L}(\theta)$ over the parameter space of $\theta$ to determine our estimate of $\theta$.

\subsection{Identification}

In this section, we briefly discuss which features of the data allow our estimation procedure to estimate particular parameters within $\theta$. First, given the short panel data of seven periods, it is not possible to identify plant-specific productivities and transport costs, for each plant due to the incidental parameters problem. For this reason, we follow the random effects approach by imposing parametric distributional assumptions as described in the previous section. ${ }^{18}$ Specifically, we assume that the distribution of $\left((\sigma-1) \ln \varphi_{i}, \ln \left(z_{i}^{x}\right), \ln \left(z_{i}^{m}\right)\right)$ is normally distributed at the time of entry and we identify their means and standard deviations, $\left(\mu^{x}, \mu^{m}, \sigma^{\varphi}, \sigma^{x}, \sigma^{m}\right)$, by exploiting variation in productivities and export/import intensities among new entrants.

The per-period fixed cost of exporting, $f^{x}$, is identified from the frequency with which exporters become non-exporters. The sunk cost of exporting, $c^{x}$, can be separately identified from the per-period fixed cost, $f^{x}$, by examining the extent to which past exporting status matters

\footnotetext{
${ }^{18}$ Nonparametric identification of unobserved heterogeneity is difficult especially in the presence of state dependence as in our model. Kasahara and Shimotsu (2008) show that it is possible to nonparametrically identify the distribution of unobserved heterogeneity when the length of panel data is sufficiently long and the covariates provide sufficient variation across different types.
} 
for current exporting frequencies, after controlling for other plant characteristics. If the sunk cost of exporting is zero, then whether a plant exported last year or not should not affect the probability of exporting; on the other hand, if a plant faces large sunk costs of exporting, then a plant that exported last year is more likely to export this year than a plant that did not export last year. Similarly the fixed and sunk costs associated with importing, $f^{m}$ and $c^{m}$, may be identified from the frequencies of importing and the extent to which past importing status affects the probability of importing.

The fixed cost of operating, $f$, is identified from the frequencies of exiting across plants with similar plant characteristics. The cost complementarity parameter, $\zeta$, is identified by comparing the frequencies of exporting among non-importers with the frequencies of exporting among importers across plants after controlling for plant characteristics.

The scale parameters for exit shocks and export/import cost shocks, $\varrho^{\chi}$ and $\varrho^{d}$, are major determinants of the elasticities of the different choice probabilities with respect to payoff relevant state variables. Consequently, the scale parameter for exit shocks, $\varrho^{\chi}$, is identified by differences in exiting frequencies across plants with different plant characteristics while we may identify scale parameters for shocks associated with export/import choices, $\varrho^{d}$, by differences in exporting and importing frequencies across plants with different plant characteristics. The elasticity of substitution in consumption, $\sigma$, is identified from average gross profit margins as specified in equation (31).

Finally, we note that our estimate of $\theta$ alone does not allow us to identify the parameters of the technology for producing final goods given in equation (3) including labor's share, $\alpha$, and the elasticity of substitution between intermediates, $\gamma$. Instead, we compute the average material shares in variable cost as our estimate of $1-\alpha$ and then use this estimate, our estimates of $\sigma$ and $\alpha_{m}$, and equation (30) to derive an estimate of $\gamma$.

\subsection{Estimation Results}

Table 6 presents a subset of the maximum likelihood estimates for each industry. ${ }^{19}$ The table also reports their asymptotic standard errors, which are computed using the outer product of gradients estimator. The parameters are evaluated in units of millions of US dollars in 1990.

The estimated elasticity of substitution in consumption across differentiated final products, $\sigma$, ranges from 3.73 for Plastic Products to 5.24 for Food Products, implying markups of price over marginal cost ranging between $24 \%$ and $37 \%$. Our estimate of the elasticity of substitution

\footnotetext{
${ }^{19}$ Estimates for the remaining parameters are presented in the appendix.
} 
Table 6: Maximum Likelihood Estimates

\begin{tabular}{c|cc|cc|cc|cc|ccc|c}
\hline Params. & \multicolumn{2}{|c|}{ Apparel } & \multicolumn{2}{c|}{ Plastics } & \multicolumn{2}{c|}{ Food } & \multicolumn{2}{c|}{ Textiles } & \multicolumn{2}{c|}{ Wood } & \multicolumn{2}{c}{ Metals } \\
\hline$\sigma$ & 4.459 & $(0.055)$ & 3.734 & $(0.036)$ & 5.239 & $(0.064)$ & 4.348 & $(0.068)$ & 5.166 & $(0.115)$ & 3.864 & $(0.034)$ \\
\hline$\alpha_{0}$ & -0.791 & $(0.012)$ & -0.526 & $(0.017)$ & -0.466 & $(0.015)$ & -0.646 & $(0.011)$ & -0.875 & $(0.020)$ & -0.755 & $(0.011)$ \\
$\alpha_{t}$ & 0.063 & $(0.003)$ & 0.172 & $(0.003)$ & 0.035 & $(0.002)$ & 0.017 & $(0.002)$ & 0.030 & $(0.003)$ & 0.074 & $(0.002)$ \\
$\alpha_{m}$ & 0.249 & $(0.058)$ & 0.202 & $(0.030)$ & 0.758 & $(0.085)$ & 0.299 & $(0.034)$ & 0.317 & $(0.134)$ & 0.227 & $(0.035)$ \\
\hline$f$ & 0.044 & $(0.008)$ & 0.124 & $(0.016)$ & 0.087 & $(0.014)$ & .089 & $(0.018)$ & .027 & $(.003)$ & 0.055 & $(0.005)$ \\
$f^{x}$ & 0.051 & $(0.012)$ & 0.036 & $(0.009)$ & 0.078 & $(0.009)$ & 0.037 & $(0.010)$ & 0.054 & $(0.006)$ & 0.081 & $(0.014)$ \\
$f^{m}$ & 0.037 & $(0.009)$ & 0.030 & $(0.009)$ & 0.117 & $(0.014)$ & 0.027 & $(0.009)$ & 0.060 & $(0.013)$ & 0.054 & $(0.010)$ \\
$c^{x}$ & 0.549 & $(0.138)$ & 0.719 & $(0.127)$ & 1.008 & $(0.102)$ & 0.812 & $(0.152)$ & 0.348 & $(0.065)$ & 0.767 & $(0.135)$ \\
$c^{m}$ & 0.478 & $(0.116)$ & 0.464 & $(0.077)$ & 0.888 & $(0.083)$ & 0.683 & $(0.125)$ & 0.478 & $(0.084)$ & 0.623 & $(0.105)$ \\
$\zeta$ & 0.796 & $(0.031)$ & 0.814 & $(0.041)$ & 0.930 & $(0.025)$ & 0.885 & $(0.034)$ & 0.742 & $(0.035)$ & .762 & $(0.029)$ \\
\hline$\mu^{x}$ & -3.704 & $(0.354)$ & -3.519 & $(0.775)$ & -0.831 & $(0.148)$ & -3.586 & $(0.826)$ & -2.522 & $(0.398)$ & -4.184 & $(0.742)$ \\
$\mu^{m}$ & -1.539 & $(0.207)$ & -0.988 & $(0.206)$ & -3.172 & $(0.268)$ & -1.522 & $(0.257)$ & -4.023 & $(1.196)$ & -1.922 & $(0.222)$ \\
$\sigma^{x}$ & 1.35 & $(0.285)$ & 1.131 & $(0.719)$ & 1.672 & $(0.161)$ & 1.278 & $(0.520)$ & 2.078 & $(0.370)$ & 1.336 & $(0.432)$ \\
$\sigma^{m}$ & 1.196 & $(0.189)$ & 1.633 & $(0.219)$ & 1.218 & $(0.207)$ & 1.219 & $(0.251)$ & 1.667 & $(0.698)$ & 1.466 & $(0.238)$ \\
$\sigma^{\varphi}$ & 1.220 & $(0.076)$ & 1.069 & $(0.074)$ & 1.242 & $(0.068)$ & 1.064 & $(0.079)$ & 1.275 & $(0.082)$ & 1.065 & $(0.049)$ \\
\hline \hline
\end{tabular}

Notes: Standard errors are in parentheses. The parameters are evaluated units of millions of US dollars in 1990. The value of $\gamma$ is calculated as $\gamma=(\sigma-1)(1-\alpha) / \alpha_{m}+1$ where $(1-\alpha)$ is computed as the mean of the material share in total variable cost.

in production across differentiated intermediate products, $\gamma$, ranges from 8.78 to $11.32 .^{20}$

\subsubsection{Sunk and Fixed Costs}

Our approach allows us to quantify the magnitude of sunk and fixed costs of exporting and importing. The average sunk cost of exporting ranges from 348 thousand 1990 US dollars for Wood Products to 1,008 thousand US dollars for Food Products. ${ }^{21}$ The sunk costs of importing range from 464 thousand 1990 US dollars for Plastic Products to 888 thousand US dollars for food products. Thus, both exporting and importing requires high start-up costs, which may arise because starting to import requires establishing a network with foreign suppliers, learning government regulations, or implementing new materials. It is important to note that

\footnotetext{
${ }^{20}$ Our estimates for the elasticity of substitution in production across differentiated intermediate products are higher than those found by Feenstra, Markusen, and Zeile (1992) and Halpern, Koren, and Szeidl (2006). For instance, the latter study finds that the elasticity of substitution between domestic and foreign intermediate goods is 5.4 .

${ }^{21}$ To the best of our knowledge, the only previous study that estimates the magnitude of sunk costs of exporting is Das, Roberts, and Tybout (2007) while there is no previous study that estimates importing sunk costs. Despite using different empirical specifications and looking at different countries and industries, our estimates of exporting sunk costs are similar in magnitude, although larger, to the estimates of Das, Roberts, and Tybout, especially given our relatively large standard errors. Their estimates range from 344 thousand 1986 US dollars to 430 thousand 1986 US dollars for leather products, basic chemicals, and knitted fabrics industries in Columbia.
} 
the exporting and importing costs actually incurred are lower than these estimates since plants start exporting and/or importing when they get lower cost shocks. Furthermore, as we discuss below, plants that both export and import pay considerably less of the sunk costs because of cost complementarities.

The fixed costs of exporting range from 36 to 81 thousand US dollars while the fixed costs of importing range from 27 to 117 thousand US dollars, indicating that both exporters and importers also pay substantial per-period fixed costs to continue to export and import. The parameter determining the degree of complementarity in exporting and importing sunk and fixed costs, $\zeta$, ranges from 0.74 to 0.93 , indicating that a firm can save between 7 and 26 percent of the per-period fixed costs and sunk costs associated with trade by simultaneously engaging in both export and import activities. Hence, the estimated total fixed costs of trading for a plant that both exports and imports ranges from 54 thousand 1990 US dollars for Plastic Products to 181 thousand 1990 US dollars for Food Products.

\subsubsection{Importing and Exporting}

The estimates of $\alpha_{m}, \mu^{x}, \mu^{m}, \sigma^{x}$, and $\sigma^{m}$ indicate that the effects of exporting and importing on total revenue differ across plants but, on average, their impact is large. In particular, for the "average" plant in an industry with $z_{i}^{x}=\exp \left(\mu^{x}\right)$ and $z_{i}^{m}=\exp \left(\mu^{m}\right)$, the revenue premium from exporting ranges from $1.5 \%$ for Metals to $36.2 \%$ for Food Products while the revenue premium from importing intermediates varies from $.6 \%$ for Wood Products to $6.4 \%$ for Plastics. ${ }^{22}$ Furthermore, the estimates of $\sigma^{x}$ and $\sigma^{m}$ suggest substantial heterogeneity in gains from exporting and importing. Note that since plants with larger gains from exporting and importing are more likely to self-select into those activities, the average revenue gains from exporting and importing among actual exporters and importers is even larger than the gain for the "average" plant.

Figure 3 compares the actual and predicted distribution of export and import intensities for one of our four digit industries, Wearing Apparel, and one of our three digit industries, Food Products. In the top panels, the solid line indicates the actual export intensities while the dashed line indicates the predicted export intensities. The empirical models quantitatively replicate the observed pattern of export intensities. The figure also plots the distribution of latent export intensities among non-exporters if they had exported. The distribution of nonexporters (dotted line) is skewed left relative to that of exporters (dashed line). This is because,

\footnotetext{
${ }^{22}$ The revenue premium from exporting is derived from the coefficient on $d_{i t}^{x}$ in equation $(26): \ln \left(1+z_{i}^{x}\right)$ while the revenue increase from importing intermediates is derived from the coefficient on $d_{i t}^{m}$ in that equation: $\alpha_{m} \ln \left(1+z_{i}^{m}\right)$.
} 

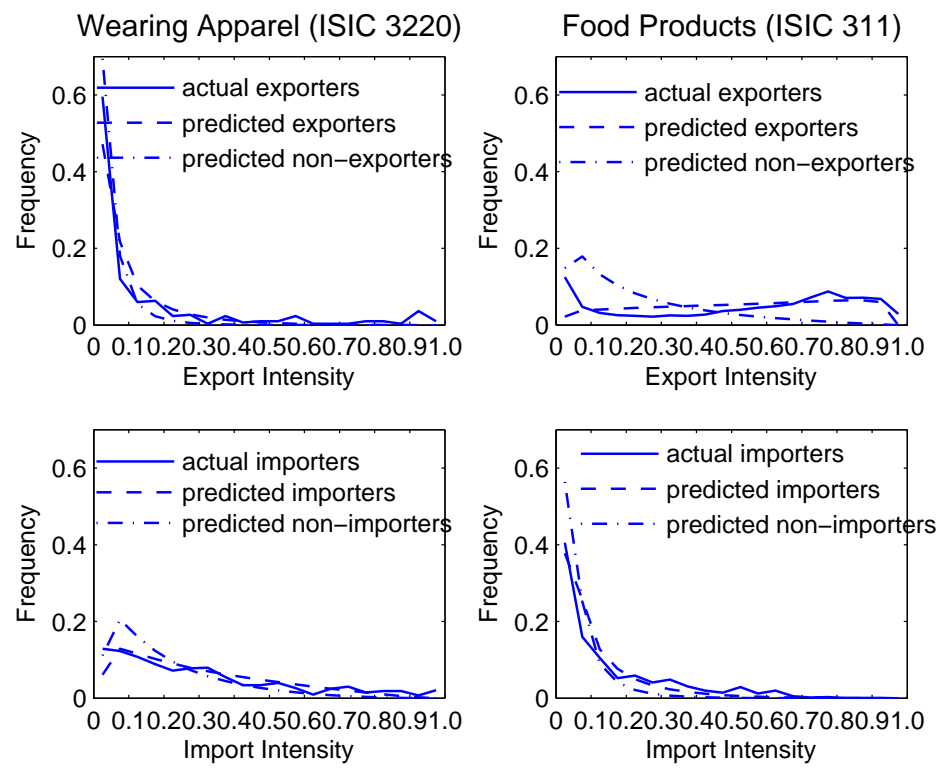

Figure 3: Export and Import Intensities (Actual vs. Predicted)

in the model, plants with lower transportation costs are more likely to export than plants with higher transportation costs. Similarly, in the bottom panels, the estimated model replicates the distribution of import intensities well and the predicted import intensities among non-importers tend to be lower than those among importers. ${ }^{23}$

Table 7 shows that exports and imports are highly concentrated in all of our industries in the data and that the estimated model performs reasonably well in capturing the observed high degree of trade concentration. For instance, in Wearing Apparel, the top 5 percent of exporting (importing) plants account for 55.4 (35.1) percent of total exports (imports) in the actual data, while the prediction of the empirical model is 40.7 (30.0) percent. ${ }^{24}$

\subsubsection{Productivity}

We now examine differences in productivity distributions between incumbents and entrants and across firms with different trade status. ${ }^{25}$ In the model, plants with higher productivity are

\footnotetext{
${ }^{23}$ The predicted distribution of import intensities is hump-shaped while the actual distribution is not. This is because we assume that transportation costs are normally distributed.

${ }^{24}$ In our preliminary investigation, we estimated a model without heterogeneity in transportation costs and found that the degree of trade concentration predicted by the model without heterogeneous transportation costs is far less than observed. Hence, not only heterogeneity in productivities but also heterogeneity in transportation costs are crucial to quantitatively explain the heavy concentration of exports and imports among a small number of plants in our data.

${ }^{25}$ ADD REFERENCES HERE TO PAPERS WHICH DEAL WITH PROBLEMS WITH APPROPRIATELY MEASURING PRODUCTIVITY INCLUDING KASAHRA AND RODRIGUE.
} 
Table 7: Export and Import Concentration (Actual vs. Predicted)

\begin{tabular}{|c|c|c|c|c|c|c|c|c|c|c|c|c|}
\hline \multirow{3}{*}{ Exports } & \multirow{2}{*}{\multicolumn{2}{|c|}{$\begin{array}{c}\text { Apparel } \\
\text { \% of Total } \\
\text { Exports }\end{array}$}} & \multirow{2}{*}{\multicolumn{2}{|c|}{$\begin{array}{l}\text { Plastics } \\
\% \text { of Total } \\
\text { Exports }\end{array}$}} & \multirow{2}{*}{\multicolumn{2}{|c|}{$\begin{array}{l}\text { Food } \\
\% \text { of Total } \\
\text { Exports }\end{array}$}} & \multirow{2}{*}{\multicolumn{2}{|c|}{$\begin{array}{l}\text { Textiles } \\
\% \text { of Total } \\
\text { Exports }\end{array}$}} & \multirow{2}{*}{\multicolumn{2}{|c|}{$\begin{array}{l}\text { Wood } \\
\text { \% of Total } \\
\text { Exports }\end{array}$}} & \multirow{2}{*}{\multicolumn{2}{|c|}{$\begin{array}{l}\text { Metals } \\
\text { \% of Total } \\
\text { Exports }\end{array}$}} \\
\hline & & & & & & & & & & & & \\
\hline & Actual & Pred. & Actual & Pred. & Actual & Pred. & Actual & Pred. & Actual & Pred. & Actual & Pred. \\
\hline Top 5\% & 55.43 & 42.45 & 46.79 & 40.34 & 24.94 & 50.66 & 51.02 & 38.02 & 42.57 & 58.92 & 34.98 & 41.04 \\
\hline Top $10 \%$ & 71.03 & 57.37 & 64.46 & 54.42 & 41.28 & 59.63 & 68.35 & 52.54 & 62.63 & 69.86 & 54.16 & 57.18 \\
\hline \multirow[t]{2}{*}{ Imports } & \multicolumn{2}{|c|}{$\begin{array}{c}\% \text { of Total } \\
\text { Imports }\end{array}$} & \multicolumn{2}{|c|}{$\begin{array}{c}\% \text { of Total } \\
\text { Imports }\end{array}$} & \multicolumn{2}{|c|}{$\begin{array}{c}\% \text { of Total } \\
\text { Imports }\end{array}$} & \multicolumn{2}{|c|}{$\begin{array}{c}\% \text { of Total } \\
\text { Imports }\end{array}$} & \multicolumn{2}{|c|}{$\begin{array}{c}\% \text { of Total } \\
\text { Imports }\end{array}$} & \multicolumn{2}{|c|}{$\begin{array}{l}\% \text { of Total } \\
\text { Imports }\end{array}$} \\
\hline & Actual & Pred. & Actual & Pred. & Actual & Pred. & Actual & Pred. & Actual & Pred. & Actual & Pred. \\
\hline Top 5\% & 35.13 & 33.95 & 38.58 & 35.10 & 44.45 & 34.05 & 40.93 & 26.01 & 39.03 & 29.77 & 42.53 & 26.24 \\
\hline Top $10 \%$ & 54.70 & 43.25 & 57.63 & 44.32 & 59.70 & 48.02 & 58.13 & 36.01 & 52.50 & 43.73 & 60.12 & 34.00 \\
\hline
\end{tabular}

Table 8: Mean of Predicted Productivity

\begin{tabular}{l|c|c|c|c|c|c}
\hline Relative Mean of $\varphi$ for & Apparel & Plastics & Food & Textiles & Wood & Metals \\
\hline Incumbents & 1.288 & 1.460 & 1.350 & 1.524 & 1.167 & 1.224 \\
Importers & 2.492 & 2.091 & 2.239 & 2.046 & 2.870 & 1.768 \\
Exporters & 2.154 & 1.809 & 1.789 & 2.216 & 2.016 & 2.112 \\
Ex/Importers & 3.257 & 2.371 & 2.631 & 2.701 & 3.279 & 2.574 \\
\hline
\end{tabular}

Notes: The reported numbers are relative to the productivity level at entry in the estimated model. In particular, the original numbers are divided by the mean of $\varphi$ at entry (i.e., $\int \varphi g_{\varphi}(\varphi) d \varphi$ ). "Exporters" are plants that export while "Importers" are plants that import. "Ex/Importers" represent plants that both export and import.

more likely to survive than lower productivity plants. Figure 5 shows the importance of such a selection mechanism for Wearing Apparel and Food Products. In the top panels, the actual productivity distribution among incumbents (solid line) is skewed right relative to the actual productivity distribution among new entrants. ${ }^{26}$ The bottom panels show that the empirical models qualitatively capture the observed difference in the productivity distributions between incumbents and new entrants. ${ }^{27}$ In Table 8, the predicted average productivity advantage of incumbents relative to that of plants attempting to enter ranges from $17 \%$ in Wood Products to $52 \%$ for Textiles, indicating that selection through endogenous exiting may play an important role in determining aggregate productivity.

Exporters and importers tend to have higher productivities than domestic plants that do not engage in any trading activities because higher productivity plants are more likely to export and import. This is shown in Figure 6 for Apparel and Food. In the top panels of the figure, the

\footnotetext{
${ }^{26}$ To construct the actual productivity distribution, we first compute a revenue residual, $\ln \varphi_{i}+\omega_{1, i t}$, for each plant-time observation as our measure of "actual productivity," and then plot a histogram of these residuals.

${ }^{27}$ The numbers used to construct Figures 4-6 as well as those reported in Tables 8-10 are directly computed using the approximated distribution function rather than simulating the data from the estimated models. The approximation methods are presented in a supplementary appendix which is available upon request.
} 

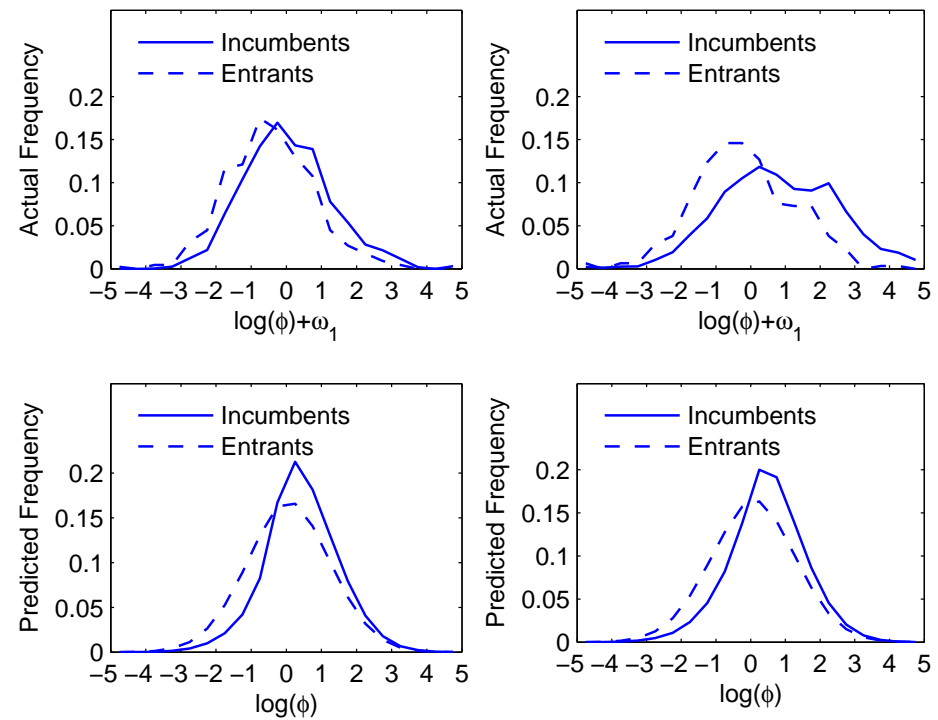

Figure 4: Productivity Distribution of Incumbents and New Entrants (Actual vs. Predicted)

Wearing Apparel (ISIC 3220)

Food Products (ISIC 311)
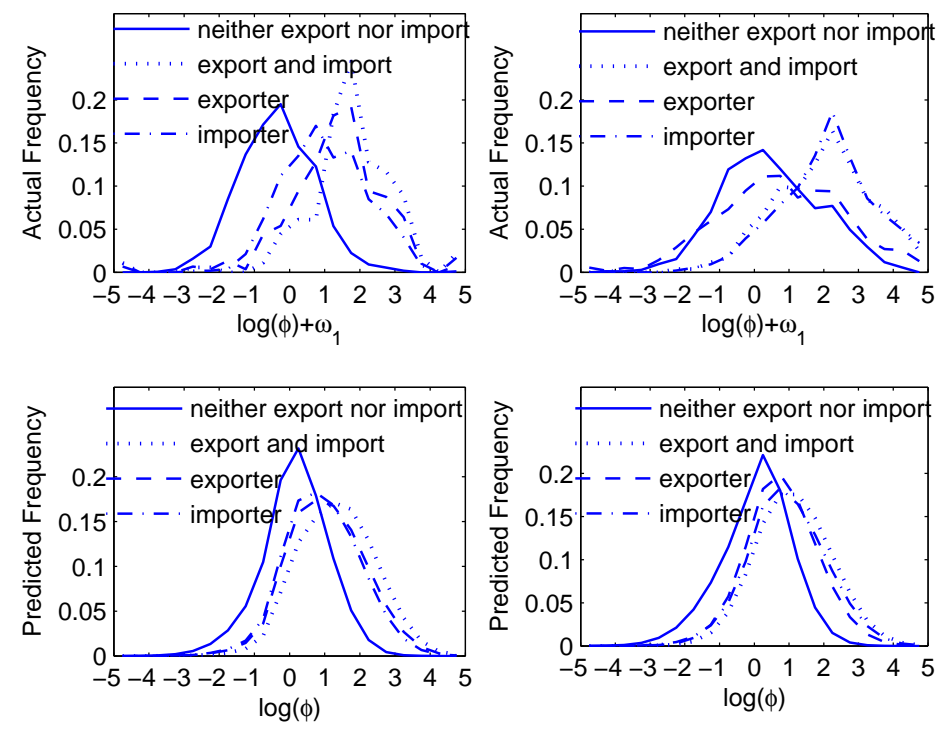

Figure 5: Productivity Distribution of Domestic Plants, Exporters, and Importers (Actual vs. Predicted) 
actual productivity distributions among plants that export, plants that import and plants that do both are skewed right relative to the actual distribution among plants that do neither. As the bottom panels show, the estimated models replicate the basic patterns of the differences in productivity distributions across plants with different trading status. This is also demonstrated in Table 8 for all the industries in our sample. The average productivity advantage of exporters and importers relative to the average incumbent is large, ranging from $24 \%$ for exporters in Plastic Products to $146 \%$ for importers in Wood Products. The table also shows that plants which both export and import are even more productive on average.

\subsubsection{Dynamics}

Table 9 shows predicted transition probabilities of export/import status conditional on not exiting from the market. The table also reports the distribution of entrants as well as the steady state distribution of plants according to export/import status. Comparing these results to those from the data in Table 4, we see that the estimated models are able to replicate the observed persistence in export/import status. The model also captures the new entrants' distribution and the steady state distribution of export/import status reasonably well. ${ }^{28}$

\subsection{Counterfactual Experiments}

We now present the results of a series of counterfactual experiments which quantify the effects of trade barriers on trading activity, productivity, and welfare in the stationary equilibria of our model economy, given the parameter estimates above. ${ }^{29}$ To quantitatively investigate the impact of trade barriers and export/import complementarities, we conduct the following six counterfactual experiments: (1) Autarky $\left(f^{x}, f^{m} \rightarrow \infty\right)$; (2) No Trade in Final Goods $\left(f^{x} \rightarrow\right.$ $\infty)$; (3) No Trade in Intermediates $\left(f^{m} \rightarrow \infty\right)$; (4) No Complementarity in Fixed Trading

\footnotetext{
${ }^{28}$ The empirical models generate the observed persistence in export/import status for the following reasons. First, the presence of sunk costs of exporting and importing generates "true state dependence" in export/import decisions. Second, unobserved heterogeneity may lead to "spurious state dependence" even without sunk costs because, for instance, highly productive plants are likely to keep exporting while less productive plants do not export. We do note, however, that the plant-specific shocks are assumed to be serially uncorrelated, and if this assumption is incorrect, the estimated effects of permanent productivity differences and/or sunk costs would be exaggerated. We also note, that if our assumption of permanent productivity differences is incorrect, and, instead, productivity follows a Markov process, then the estimated effects of sunk costs is understated. Finally, note that estimates from a model without sunk costs, presented in the appendix, do not replicate the observed high degree of persistence in export/import status. Thus, with serially uncorrelated shocks and permanent productivity differences, it is important to incorporate sunk costs to capture the observed persistence in export/import status.

${ }^{29}$ We can investigate the impact of the counterfactual experiments on welfare by examining the aggregate price response. Recall that aggregate income is constant at the level of $L$. From the budget constraint $P Q=L$ we have that aggregate utility is given by $U=Q=P^{-1} L$.
} 
Table 9: Predicted Transition Probabilities and Distributions of Export and Import Status

\begin{tabular}{|c|c|c|c|c|c|c|c|c|}
\hline & \multicolumn{4}{|c|}{ Wearing Apparel } & \multicolumn{4}{|c|}{ Plastic Products } \\
\hline & $\begin{array}{l}\text { No Exp/ } \\
\text { No Imp }\end{array}$ & $\begin{array}{c}\text { Exp/ } \\
\text { No Imp }\end{array}$ & $\begin{array}{l}\text { No Exp/ } \\
\text { Imp }\end{array}$ & $\begin{array}{l}\text { Exp/ } \\
\text { Imp }\end{array}$ & $\begin{array}{c}\text { No Exp/ } \\
\text { No Imp }\end{array}$ & $\begin{array}{c}\text { Exp/ } \\
\text { No Imp }\end{array}$ & $\begin{array}{c}\text { No Exp/ } \\
\text { Imp }\end{array}$ & $\begin{array}{l}\text { Exp/ } \\
\text { Imp }\end{array}$ \\
\hline No Exp/No Imp & 0.887 & 0.032 & 0.067 & 0.014 & 0.823 & 0.028 & 0.125 & 0.023 \\
\hline Exp/No Imp & 0.206 & 0.641 & 0.017 & 0.136 & 0.143 & 0.575 & 0.042 & 0.240 \\
\hline No $\operatorname{Exp} / \operatorname{Imp}$ & 0.196 & 0.007 & 0.716 & 0.081 & 0.191 & 0.012 & 0.703 & 0.094 \\
\hline Exp/Imp & 0.036 & 0.122 & 0.145 & 0.697 & 0.029 & 0.154 & 0.159 & 0.659 \\
\hline Entrants Dist. & 0.859 & 0.037 & 0.076 & 0.027 & 0.779 & 0.028 & 0.154 & 0.038 \\
\hline \multirow[t]{3}{*}{ Steady State Dist. } & 0.633 & 0.085 & 0.181 & 0.101 & 0.487 & 0.087 & 0.274 & 0.152 \\
\hline & \multicolumn{4}{|c|}{ Food Products } & \multicolumn{4}{|c|}{ Textiles } \\
\hline & $\begin{array}{l}\text { No Exp/ } \\
\text { No Imp }\end{array}$ & $\begin{array}{c}\text { Exp/ } \\
\text { No Imp }\end{array}$ & $\begin{array}{c}\text { No Exp/ } \\
\text { Imp }\end{array}$ & $\begin{array}{l}\text { Exp/ } \\
\operatorname{Imp}\end{array}$ & $\begin{array}{c}\text { No Exp/ } \\
\text { No Imp }\end{array}$ & $\begin{array}{c}\text { Exp/ } \\
\text { No Imp }\end{array}$ & $\begin{array}{c}\text { No Exp/ } \\
\text { Imp }\end{array}$ & $\begin{array}{l}\text { Exp/ } \\
\text { Imp }\end{array}$ \\
\hline No Exp/No Imp & 0.845 & 0.091 & 0.053 & 0.011 & 0.833 & 0.051 & 0.101 & 0.015 \\
\hline Exp/No Imp & 0.069 & 0.832 & 0.005 & 0.095 & 0.157 & 0.683 & 0.020 & 0.141 \\
\hline No $\operatorname{Exp} / \operatorname{Imp}$ & 0.316 & 0.035 & 0.555 & 0.095 & 0.162 & 0.011 & 0.744 & 0.083 \\
\hline $\operatorname{Exp} / \operatorname{Imp}$ & 0.014 & 0.199 & 0.027 & 0.759 & 0.027 & 0.125 & 0.132 & 0.716 \\
\hline Entrants Dist. & 0.686 & 0.213 & 0.044 & 0.056 & 0.821 & 0.053 & 0.105 & 0.021 \\
\hline \multirow[t]{3}{*}{ Steady State Dist. } & 0.400 & 0.376 & 0.058 & 0.165 & 0.485 & 0.128 & 0.245 & 0.142 \\
\hline & \multicolumn{4}{|c|}{ Wood Products } & \multicolumn{4}{|c|}{ Fabricated Metals } \\
\hline & $\begin{array}{l}\text { No Exp/ } \\
\text { No Imp }\end{array}$ & $\begin{array}{c}\text { Exp/ } \\
\text { No Imp }\end{array}$ & $\begin{array}{c}\text { No Exp/ } \\
\text { Imp }\end{array}$ & $\begin{array}{l}\text { Exp/ } \\
\text { Imp }\end{array}$ & $\begin{array}{c}\text { No Exp/ } \\
\text { No Imp }\end{array}$ & $\begin{array}{c}\text { Exp/ } \\
\text { No Imp }\end{array}$ & $\begin{array}{c}\text { No Exp/ } \\
\text { Imp }\end{array}$ & $\begin{array}{l}\text { Exp/ } \\
\text { Imp }\end{array}$ \\
\hline No $\operatorname{Exp} /$ No Imp & 0.938 & 0.048 & 0.008 & 0.006 & 0.906 & 0.021 & 0.062 & 0.012 \\
\hline Exp/No Imp & 0.130 & 0.819 & 0.001 & 0.050 & 0.264 & 0.592 & 0.019 & 0.126 \\
\hline No $\operatorname{Exp} / \operatorname{Imp}$ & 0.328 & 0.018 & 0.528 & 0.125 & 0.238 & 0.006 & 0.696 & 0.060 \\
\hline Exp/Imp & 0.028 & 0.189 & 0.049 & 0.734 & 0.062 & 0.144 & 0.191 & 0.602 \\
\hline Entrants Dist. & 0.833 & 0.129 & 0.008 & 0.030 & 0.895 & 0.022 & 0.067 & 0.016 \\
\hline Incumbents Dist. & 0.708 & 0.217 & 0.017 & 0.058 & 0.712 & 0.056 & 0.172 & 0.060 \\
\hline
\end{tabular}

Notes: The first four rows for each industry are the probabilities of moving from the trade status listed in the row to the trade status listed in the column in the next period.

Costs $(\zeta=1)$; (5) The transportation cost of exporting, $\tau_{x}$, increases by $10 \%$; and (6) The transportation cost of importing, $\tau_{m}$, increases by $10 \%$.

To determine the full impact of a counterfactual experiment, it is necessary to compute how the equilibrium aggregate price changes as a result of the experiment because the "reduced-form" parameter $\alpha_{0}$ in the revenue function given by (26) depends on the aggregate price, see (30). This can be done by finding a new equilibrium aggregate price at which the free entry condition (17) holds in the experiment. The appendix provides a detailed description of our approach.

Table 10 presents the results of the counterfactual experiments using the estimated models. According to these experiments, moving from autarky to trade increases real income by between $3.0 \%$ for Fabricated Metals to $23.8 \%$ for Food Products, suggesting that there are substantial increases in welfare due to trade. This positive welfare effect occurs because under trade, more productive firms start exporting and importing, which in turn increases aggregate labor demand and the real wage.

The impact of trade on aggregate productivity, measured by a productivity average using 
Table 10: Counterfactual Experiments

\begin{tabular}{|c|c|c|c|c|c|c|c|}
\hline & & \multicolumn{6}{|c|}{ Counterfactual Experiments } \\
\hline & $\begin{array}{l}\text { Free } \\
\text { Trade }\end{array}$ & Autarky & $\begin{array}{l}\text { No Trade in } \\
\text { Final Goods }\end{array}$ & $\begin{array}{c}\text { No Trade in } \\
\text { Intermediates }\end{array}$ & $\begin{array}{c}\text { No } \\
\text { Complement. }\end{array}$ & $\begin{array}{l}10 \% \text { inc. } \\
\text { in } \tau_{x}\end{array}$ & $\begin{array}{l}10 \% \text { inc. } \\
\text { in } \tau_{m}\end{array}$ \\
\hline \multicolumn{8}{|l|}{ Wearing Apparel } \\
\hline$\Delta \ln P$ & 0.000 & 0.031 & 0.014 & 0.020 & 0.004 & 0.003 & 0.007 \\
\hline$\Delta \ln ($ Average $\varphi)$ & 0.000 & -0.025 & -0.011 & -0.010 & 0.005 & -0.003 & -0.009 \\
\hline$\Delta \ln ($ Average TFP $)$ & 0.000 & -0.101 & -0.013 & -0.086 & 0.003 & -0.003 & -0.055 \\
\hline Fraction of Exporters & 0.186 & 0.000 & 0.000 & 0.125 & 0.123 & 0.169 & 0.176 \\
\hline Fraction of Importers & 0.281 & 0.000 & 0.231 & 0.000 & 0.229 & 0.278 & 0.223 \\
\hline Exports & 1.000 & 0.000 & 0.000 & 0.860 & 0.893 & 0.686 & 0.938 \\
\hline Imports & 1.000 & 0.000 & 0.890 & 0.000 & 0.925 & 0.978 & 0.389 \\
\hline \multicolumn{8}{|l|}{ Plastic Products } \\
\hline$\Delta \ln P$ & 0.000 & 0.064 & 0.020 & 0.050 & 0.006 & 0.003 & 0.015 \\
\hline$\Delta \ln ($ Average $\varphi)$ & 0.000 & -0.007 & -0.003 & 0.003 & 0.007 & -0.002 & -0.006 \\
\hline$\Delta \ln ($ Average TFP $)$ & 0.000 & -0.138 & -0.004 & -0.128 & 0.006 & -0.002 & -0.073 \\
\hline Fraction of Exporters & 0.330 & 0.000 & 0.000 & 0.234 & 0.227 & 0.309 & 0.322 \\
\hline Fraction of Importers & 0.486 & 0.000 & 0.444 & 0.000 & 0.442 & 0.485 & 0.420 \\
\hline Exports & 1.000 & 0.000 & 0.000 & 0.841 & 0.895 & 0.751 & 0.934 \\
\hline Imports & 1.000 & 0.000 & 0.945 & 0.000 & 0.976 & 0.987 & 0.518 \\
\hline \multicolumn{8}{|l|}{ Food Products } \\
\hline$\Delta \ln P$ & 0.000 & 0.238 & 0.227 & 0.014 & 0.001 & 0.055 & 0.003 \\
\hline$\Delta \ln ($ Average $\varphi)$ & 0.000 & -0.038 & -0.024 & -0.007 & 0.002 & -0.001 & -0.002 \\
\hline$\Delta \ln ($ Average $\mathrm{TFP})$ & 0.000 & -0.107 & -0.027 & -0.077 & 0.001 & -0.002 & -0.027 \\
\hline Fraction of Exporters & 0.541 & 0.000 & 0.000 & 0.545 & 0.531 & 0.502 & 0.541 \\
\hline Fraction of Importers & 0.223 & 0.000 & 0.200 & 0.000 & 0.195 & 0.223 & 0.202 \\
\hline Exports & 1.000 & 0.000 & 0.000 & 0.980 & 1.002 & 0.636 & 0.979 \\
\hline Imports & 1.000 & 0.000 & 0.273 & 0.000 & 0.976 & 0.736 & 0.657 \\
\hline \multicolumn{8}{|l|}{ Textiles } \\
\hline$\Delta \ln P$ & 0.000 & 0.049 & 0.020 & 0.033 & 0.004 & 0.003 & 0.008 \\
\hline$\Delta \ln ($ Average $\varphi)$ & 0.000 & -0.005 & -0.002 & 0.001 & 0.005 & -0.002 & -0.006 \\
\hline$\Delta \ln ($ Average TFP $)$ & 0.000 & -0.101 & -0.003 & -0.095 & 0.004 & -0.002 & -0.056 \\
\hline Fraction of Exporters & 0.270 & 0.000 & 0.000 & 0.226 & 0.221 & 0.252 & 0.266 \\
\hline Fraction of Importers & 0.387 & 0.000 & 0.358 & 0.000 & 0.355 & 0.386 & 0.335 \\
\hline Exports & 1.000 & 0.000 & 0.000 & 0.910 & 0.941 & 0.693 & 0.951 \\
\hline Imports & 1.000 & 0.000 & 0.946 & 0.000 & 0.971 & 0.983 & 0.502 \\
\hline \multicolumn{8}{|l|}{ Wood Products } \\
\hline$\Delta \ln P$ & 0.000 & 0.120 & 0.119 & 0.004 & 0.001 & 0.035 & 0.001 \\
\hline$\Delta \ln ($ Average $\varphi)$ & 0.000 & -0.028 & -0.022 & -0.004 & 0.001 & -0.001 & -0.002 \\
\hline$\Delta \ln ($ Average TFP $)$ & 0.000 & -0.048 & -0.025 & -0.023 & 0.000 & -0.002 & -0.013 \\
\hline Fraction of Exporters & 0.274 & 0.000 & 0.000 & 0.258 & 0.257 & 0.246 & 0.273 \\
\hline Fraction of Importers & 0.075 & 0.000 & 0.029 & 0.000 & 0.029 & 0.072 & 0.062 \\
\hline Exports & 1.000 & 0.000 & 0.000 & 0.984 & 0.996 & 0.638 & 0.990 \\
\hline Imports & 1.000 & 0.000 & 0.335 & 0.000 & 0.807 & 0.786 & 0.449 \\
\hline \multicolumn{8}{|l|}{ Fabricated Metals } \\
\hline$\Delta \ln P$ & 0.000 & 0.030 & 0.011 & 0.024 & 0.005 & 0.001 & 0.005 \\
\hline$\Delta \ln ($ Average $\varphi)$ & 0.000 & -0.014 & -0.006 & -0.005 & 0.003 & -0.002 & -0.006 \\
\hline$\Delta \ln ($ Average $\mathrm{TFP})$ & 0.000 & -0.071 & -0.008 & -0.063 & 0.000 & -0.002 & -0.037 \\
\hline Fraction of Exporters & 0.116 & 0.000 & 0.000 & 0.062 & 0.060 & 0.109 & 0.110 \\
\hline Fraction of Importers & 0.232 & 0.000 & 0.186 & 0.000 & 0.185 & 0.230 & 0.201 \\
\hline Exports & 1.000 & 0.000 & 0.000 & 0.764 & 0.768 & 0.720 & 0.941 \\
\hline Imports & 1.000 & 0.000 & 0.893 & 0.000 & 0.899 & 0.987 & 0.491 \\
\hline
\end{tabular}


the plants' market shares as weights, can be understood by comparing "ln(Average $\varphi$ )" at the steady state between trade and autarky. Moving from trade to autarky decreases this measure of aggregate productivity at the steady state by between $0.5 \%$ for Textiles and $3.8 \%$ for Food Products. Note that once we take into account the additional productivity effect arising from importing intermediates, the impact of trade on total factor productivity (TFP) is much larger at $10.1 \%$ and $10.7 \%$ for those two industries. Comparing these effects, we see that most of TFP effect of trade is induced by importing intermediates. ${ }^{30}$

The counterfactual experiments under no trade in final goods or no trade in intermediates (but not both) highlight the interaction between exporting and importing in the presence of heterogeneous firms. According to the estimated models, when the economy moves from full trade to no trade in final goods, both the fraction of importers of intermediates and the level of imported intermediates declines in all of our industries. Furthermore, when the economy moves from full trade to no trade in intermediates, the fraction of exporters of final goods falls in all industries except Food Products while total exports of final goods decline in all industries. ${ }^{31}$ Thus, generally policies that prohibit the import of foreign materials could have a large negative impact on the export of final consumption goods - that is, import protection can lead to export destruction.

We now briefly examine the role of complementarities between export and import fixed and sunk costs relative to the role played by the complementarities in the revenue function. To do so we conducted an experiment to determine what would happen to the fraction of importers and the fraction of exporters if there was no complementarity between exporting and importing in the fixed and sunk cost functions. We find that eliminating cost complementarities lowers the fraction of exporters and importers as well as aggregate exports and imports for all of our industries, providing evidence that the cost complementarities play a role in inducing plants to both export and import simultaneously.

We conduct additional (less extreme) experiments to examine what would happen to welfare

\footnotetext{
${ }^{30}$ We note that if our model is misspecified in some dimension which affects firm productivity, such as changes in the mix of products produced by firms, then our estimates of the effect of trade on productivity will be biased. We also remind the reader that our assumption of no entry into the intermediates good sector implies that our model does not capture the full general equilibrium effects on welfare, resource allocation, and productivity of trade liberalization. In particular, if there were free entry into that sector, increased trade would presumably induce resource allocations within intermediate goods producers as well as additional reallocations between intermediate and final good producers. However, since we assume that the measure of intermediates produced within a country is fixed and in our estimation we treat all producers as final good suppliers, we miss some of these resource reallocations that might affect our measures of welfare and productivity gains.

${ }^{31}$ For Food Products, the fraction of exporters rises slightly when trade in intermediates is restricted because of the relatively large price effect.
} 
and productivity if the transportation cost parameters, $\tau_{x}$ and $\tau_{m}$, were $10 \%$ higher than the actual estimates. The results are presented in columns (5) and (6) of Table 10. Note that a 10 percent increase in transportation costs of either form have a relatively small impact on the fraction of exporters and importers but a substantial impact on aggregate exports and imports. This implies that the impact of an increase in transportation costs (or tariffs) on aggregate exports and imports operates mainly through the intensive margin rather than through the extensive margin. This finding is consistent with the findings of Das, Roberts, and Tybout (2007).

\subsection{Non-Stationarity}

The basic specification focuses on a stationary equilibrium in which all aggregate variables are constant over time. In this section, we allow for elements on non-stationarity and examine the sensitivity of our basic results to these changes. Firstly, as Das et al. (2007) argue, exchange rate shocks may be one of the major determinants of firm's decision to trade. Furthermore, the Chilean real exchange rate gradually appreciated by $22 \%$ over our sample period. Hence, we incorporate exchange rate shocks into our empirical model. Secondly, export and import intensities may trend over time due to changes in transport costs or differences in growth rates between Chile and the rest of world. Thus, we explicitly incorporate time trends in transport costs into the empirical model. Details of the procedure and full results are given in the appendix.

First we briefly describe how we incorporate exchange rate shocks into our basic framework. We assume that the log of the exchange rate follows an exogenous first order autoregressive process and estimate the parameters of the process by OLS using data from 1980-2007. The exchange rate shock enters on the right-hand side of the revenue equation given by 26 with coefficient $\alpha_{e}$. Now in the presence of such an aggregate shock, the exchange rate as well as the distribution of firms' types and trade status $\left(\eta_{i}\right.$ and $\left.d_{i t}\right)$ among incumbents become state variables as this distribution is necessary to form expectations about the future aggregate price (cf., Krusell and Smith (1997)). Allowing for the distribution to be a state variable for firms' dynamic decisions makes it computationally impossible to estimate the model because it requires solving the equilibrium law of motion for the distribution for each candidate parameter vector. For this reason, we assume that firms are bounded rational such that they believe that aggregate revenue and price are not affected by the distribution of $\eta_{i}$ and $d_{i t}$ once the exchange rate as well as time trend is taken into account. Thus, similar to Das et al. (2007), we estimate a single agent dynamic programming model with exogenous exchange rate shocks. 
We also extend the basic model by allowing for a time trend in export and import intensities. In the context of the model, a time trend in export and import intensities may arise because of differences between the growth rate of Chile and that of the rest of world. We model this by allowing the number of trading partners to trend: $N_{t}=N \exp \left(\alpha_{N} t\right)$, where a negative $\alpha_{N}$ implies faster growth in Chile than in the rest of the world. In addition, trade intensities will trend over time with trends in transport costs which we directly incorporate into the model: i.e. $\tau_{i t}^{x}=\tau_{i}^{x} \exp \left(\tilde{\alpha}_{t}^{x} t\right)$ and $\tau_{i t}^{m}=\tau_{i}^{m} \exp \left(\tilde{\alpha}_{t}^{m} t\right)$. As described in the appendix, we can only identify up to a linear relationship of these parameters given by $\alpha_{t}^{x}=\tilde{\alpha}_{t}^{x}+\alpha_{N} /(1-\sigma)$ and $\alpha_{t}^{m}=\tilde{\alpha}_{t}^{m}+\alpha_{N} /(1-\gamma)$. The rest of estimation procedure is similar to what is described in Section 4.1 above.

The maximum likelihood estimates for select parameters under these modifications is reported in Table 11. Given the gradual appreciation of the real exchange rate in the sample, it seems difficult to separately identify the effect of the real exchange rate on revenue separately from the time-trend; the coefficients on the real exchange rate in the revenue function is negative for Apparel and positive for other industries while the time trend term is estimated nearly at zero for all industries except for Apparel. The signs of the estimated time trend terms for export intensity, $\alpha_{t}^{x}$, are mixed across the industries while the trend terms for import intensity, $\alpha_{t}^{m}$, are positive for all industries. As discussed above, these latter positive estimates may reflect the higher growth of the domestic market relative to foreign market given the high growth rate of the Chilean economy from 1990 to 1996. Our estimates of cost parameters are similar in magnitude to those under the basic specification.

We also use the estimated parameters to conduct counterfactual experiments in a way comparable to the experiments conducted in the previous section. In Table 12, we report the results of a subset of the counterfactual experiments of the modified model. Comparing these results to those given in Table 10, we see that the findings are similar to that of the basic model in that there continue to be significant welfare and productivity gains to trade. These gains are not systematically larger nor smaller across our industries under these modifications relative to the basic model. Furthermore, our finding in the basic model that prohibiting one type of trade lowers the other type of trade (through both the extensive and intensive margins) is robust to this modification for nearly all of our industries.

We end this section by noting that the appendix contains additional robustness exercises regarding the specification of trade shocks and the sensitivity of the results to the inclusion of sunk costs. As the results in the appendix demonstrate, our basic findings continue to hold in 
Table 11: Select Parameter Estimates in Non-Stationary Model

\begin{tabular}{|c|c|c|c|c|c|c|c|c|c|c|c|c|}
\hline Parameters & \multicolumn{2}{|c|}{ Apparel } & \multicolumn{2}{|c|}{ Plastics } & \multicolumn{2}{|c|}{ Food } & \multicolumn{2}{|c|}{ Textiles } & \multicolumn{2}{|c|}{ Wood } & \multicolumn{2}{|c|}{ Metals } \\
\hline$\sigma$ & 4.399 & $(0.054)$ & 3.706 & $(0.038)$ & 4.873 & $(0.053)$ & 4.223 & $(0.064)$ & 4.932 & $(0.103)$ & 3.826 & $(0.034)$ \\
\hline$\alpha_{0}$ & -1.192 & $(0.216)$ & 0.494 & $(0.015)$ & -0.350 & $(0.155)$ & -0.545 & $(0.038)$ & -0.662 & $(0.027)$ & -0.330 & $(0.180)$ \\
\hline$\alpha_{m}$ & 0.260 & $(0.042)$ & 0.206 & $(0.023)$ & 0.400 & $(0.030)$ & 0.302 & $(0.030)$ & 0.379 & $(0.067)$ & 0.339 & $(0.039)$ \\
\hline$\alpha_{t}$ & 0.132 & $(0.037)$ & 0.000 & $(0.000)$ & 0.030 & $(0.026)$ & 0.000 & $(0.006)$ & 0.000 & $(0.003)$ & 0.002 & $(0.031)$ \\
\hline$\alpha_{e}$ & -1.811 & $(0.973)$ & 4.733 & $(0.084)$ & 0.650 & $(0.700)$ & 0.480 & $(0.175)$ & 1.073 & $(0.116)$ & 1.985 & $(0.810)$ \\
\hline$\alpha_{t}^{x}$ & 0.041 & $(0.011)$ & 0.043 & $(0.009)$ & -0.021 & $(0.001)$ & 0.009 & $(0.005)$ & -0.018 & $(0.003)$ & 0.012 & $(0.008)$ \\
\hline$\alpha_{t}^{m}$ & 0.034 & $(0.002)$ & 0.035 & $(0.002)$ & 0.032 & $(0.002)$ & 0.025 & $(0.002)$ & 0.036 & $(0.005)$ & 0.034 & $(0.003)$ \\
\hline$f$ & 0.037 & $(0.008)$ & 0.325 & $(0.051)$ & 0.115 & $(0.173)$ & 0.099 & $(0.020)$ & 0.044 & $(0.011)$ & 0.085 & $(0.016)$ \\
\hline$f_{x}$ & 0.037 & $(0.010)$ & 0.057 & $(0.017)$ & 0.092 & $(0.015)$ & 0.038 & $(0.011)$ & 0.078 & $(0.009)$ & 0.121 & $(0.026)$ \\
\hline$f_{m}$ & 0.030 & $(0.007)$ & 0.065 & $(0.017)$ & 0.090 & $(0.017)$ & 0.030 & $(0.010)$ & 0.089 & $(0.017)$ & 0.099 & $(0.020)$ \\
\hline$c_{x}$ & 0.522 & $(0.104)$ & 1.400 & $(0.231)$ & 1.450 & $(0.196)$ & 0.918 & $(0.159)$ & 0.562 & $(0.099)$ & 1.362 & $(0.259)$ \\
\hline$c_{m}$ & 0.440 & $(0.088)$ & 0.883 & $(0.140)$ & 1.330 & $(0.170)$ & 0.756 & $(0.128)$ & 0.758 & $(0.133)$ & 1.065 & $(0.201)$ \\
\hline$\zeta$ & 0.798 & $(0.031)$ & 0.816 & $(0.041)$ & 0.918 & $(0.025)$ & 0.888 & $(0.034)$ & 0.734 & $(0.031)$ & 0.763 & $(0.029)$ \\
\hline log-likelihood & \multicolumn{2}{|c|}{-3800.41} & \multicolumn{2}{|c|}{-3754.81} & \multicolumn{2}{|c|}{-10627.79} & \multicolumn{2}{|c|}{-5773.35} & \multicolumn{2}{|c|}{-5029.44} & \multicolumn{2}{|c|}{-4937.61} \\
\hline
\end{tabular}

Notes: Standard errors are in parentheses. The parameters are evaluated units of millions of US dollars in 1990.

those exercises.

\section{Conclusions and Extensions}

We have developed and estimated a stochastic industry model of importing and exporting with heterogeneous firms. The analysis highlights interactions between imports of intermediate goods and exports of final goods. In doing so, we have identified a potential mechanism whereby import policy can affect exports and export policy can affect imports.

Our model has a simple parsimonious structure and, yet, is able to replicate the basic features of the plant-level data. To maintain its parsimony, and also because of data limitations and computational complexity, the model ignores several important features. We do not address the important issue of how multi-plant and multinational firms make joint decisions on exporting and importing across different plants. We also ignore plant capital investment decisions. Finally, we do not allow adjustment in the measure of varieties of intermediates produced within a country in response to changes in the trading environment. These features could be incorporated into our theoretical and empirical framework and such extensions are important topics for our future research. 
Table 12: Counterfactual Experiments for Non-Stationary Model

\begin{tabular}{|c|c|c|c|c|c|c|c|c|}
\hline & \multicolumn{4}{|c|}{ Apparel } & \multicolumn{4}{|c|}{ Plastics } \\
\hline & $\begin{array}{c}\text { Free } \\
\text { Trade }\end{array}$ & Autarky & $\begin{array}{l}\text { No Trade in } \\
\text { Final Goods }\end{array}$ & $\begin{array}{l}\text { No Trade in } \\
\text { Intermediates }\end{array}$ & $\begin{array}{c}\text { Free } \\
\text { Trade }\end{array}$ & Autarky & $\begin{array}{l}\text { No Trade in } \\
\text { Final Goods }\end{array}$ & $\begin{array}{l}\text { No Trade in } \\
\text { Intermediates }\end{array}$ \\
\hline$\Delta \ln P$ & 0.000 & 0.020 & 0.009 & 0.014 & 0.000 & 0.031 & 0.009 & 0.026 \\
\hline$\Delta \ln ($ Average $\varphi)$ & 0.000 & -0.026 & -0.013 & -0.006 & 0.000 & -0.010 & -0.005 & 0.002 \\
\hline$\Delta \ln ($ Average TFP $)$ & 0.000 & -0.113 & -0.016 & -0.093 & 0.000 & -0.128 & -0.007 & -0.116 \\
\hline Fraction of Exporters & 0.213 & 0.000 & 0.000 & 0.144 & 0.351 & 0.000 & 0.000 & 0.243 \\
\hline Fraction of Importers & 0.288 & 0.000 & 0.230 & 0.000 & 0.472 & 0.000 & 0.426 & 0.000 \\
\hline Exports & 1.000 & 0.000 & 0.000 & 0.851 & 1.000 & 0.000 & 0.000 & 0.833 \\
\hline \multirow[t]{3}{*}{ Imports } & 1.000 & 0.000 & 0.862 & 0.000 & 1.000 & 0.000 & 0.906 & 0.000 \\
\hline & \multicolumn{4}{|c|}{ Food } & \multicolumn{4}{|c|}{ Textiles } \\
\hline & $\begin{array}{c}\text { Free } \\
\text { Trade }\end{array}$ & Autarky & $\begin{array}{l}\text { No Trade in } \\
\text { Final Goods }\end{array}$ & $\begin{array}{c}\text { No Trade in } \\
\text { Intermediates }\end{array}$ & $\begin{array}{c}\text { Free } \\
\text { Trade }\end{array}$ & Autarky & $\begin{array}{l}\text { No Trade in } \\
\text { Final Goods }\end{array}$ & $\begin{array}{c}\text { No Trade in } \\
\text { Intermediates }\end{array}$ \\
\hline$\Delta \ln P$ & 0.000 & 0.943 & 0.940 & 0.001 & 0.000 & 0.037 & 0.016 & 0.025 \\
\hline$\Delta \ln ($ Average $\varphi)$ & 0.000 & -0.064 & -0.062 & -0.004 & 0.000 & -0.003 & -0.003 & 0.004 \\
\hline$\Delta \ln ($ Average TFP $)$ & 0.000 & -0.098 & -0.057 & -0.037 & 0.000 & -0.087 & -0.005 & -0.080 \\
\hline Fraction of Exporters & 0.582 & 0.000 & 0.000 & 0.570 & 0.282 & 0.000 & 0.000 & 0.237 \\
\hline Fraction of Importers & 0.250 & 0.000 & 0.533 & 0.000 & 0.375 & 0.000 & 0.344 & 0.000 \\
\hline Exports & 1.000 & 0.000 & 0.000 & 0.979 & 1.000 & 0.000 & 0.000 & 0.920 \\
\hline \multirow[t]{3}{*}{ Imports } & 1.000 & 0.000 & 0.365 & 0.000 & 1.000 & 0.000 & 0.925 & 0.000 \\
\hline & \multicolumn{4}{|c|}{ Wood } & \multicolumn{4}{|c|}{ Metals } \\
\hline & $\begin{array}{c}\text { Free } \\
\text { Trade }\end{array}$ & Autarky & $\begin{array}{l}\text { No Trade in } \\
\text { Final Goods }\end{array}$ & $\begin{array}{c}\text { No Trade in } \\
\text { Intermediates }\end{array}$ & $\begin{array}{c}\text { Free } \\
\text { Trade }\end{array}$ & Autarky & $\begin{array}{l}\text { No Trade in } \\
\text { Final Goods }\end{array}$ & $\begin{array}{c}\text { No Trade in } \\
\text { Intermediates }\end{array}$ \\
\hline$\Delta \ln P$ & 0.000 & 0.576 & 0.575 & 0.001 & 0.000 & 0.026 & 0.010 & 0.021 \\
\hline$\Delta \ln ($ Average $\varphi)$ & 0.000 & -0.037 & -0.033 & -0.003 & 0.000 & -0.020 & -0.008 & -0.010 \\
\hline$\Delta \ln ($ Average TFP $)$ & 0.000 & -0.066 & -0.031 & -0.032 & 0.000 & -0.106 & -0.012 & -0.096 \\
\hline Fraction of Exporters & 0.275 & 0.000 & 0.000 & 0.255 & 0.125 & 0.000 & 0.000 & 0.063 \\
\hline Fraction of Importers & 0.073 & 0.000 & 0.084 & 0.000 & 0.229 & 0.000 & 0.182 & 0.000 \\
\hline Exports & 1.000 & 0.000 & 0.000 & 0.978 & 1.000 & 0.000 & 0.000 & 0.664 \\
\hline Imports & 1.000 & 0.000 & 0.592 & 0.000 & 1.000 & 0.000 & 0.889 & 0.000 \\
\hline
\end{tabular}




\section{References}

[1] Amiti, M. and J. Konings (2005) "Trade Liberalization, Intermediate Inputs, and Productivity: Evidence from Indonesia," IMF Working Paper 05/146.

[2] Atkeson, Andrew and Ariel Burstein (2007) "Innovation, Firm Dynamics, and International Trade," NBER Working Paper No. 13326.

[3] Aw, Bee Yan, Sukkyun Chung, and Mark J. Roberts (2000) "Productivity and Turnover in the Export Market: Micro-level Evidence from the Republic of Korea and Taiwan(China)," World Bank Economic Review, 14, 65-90.

[4] Ben-Akiva, Moshe and Moshe Lerman (1985) Discrete Choice Analysis: Theory and Application to Travel Demand, MIT Press, Cambridge, MA.

[5] Bernard, Andrew B. and J. Bradford Jensen (1999) "Exceptional Exporter Performance: Cause, Effect, and or Both?" Journal of International Economics, 47: 1-25.

[6] Bernard, Andrew B., Jonathan Eaton, J. Bradford Jensen, and Samuel Kortum (2003) "Plants and Productivity in International Trade," American Economic Review, 93(4): 1268-1290.

[7] Bernard, Andrew B., S. Redding, and P. Schott (2007) "Comparative Advantage and Heterogeneous Firms," Review of Economic Studies, 74(1), 31-66.

[8] Bernard, Andrew B., J. Bradford Jensen, and Peter K. Schott (2005) "Importers, Exporters, and Multinationals: A Portrait of Firms in the U.S. that Trade Goods," NBER Working Paper 11404.

[9] Brooks, Eileen (2006) "Why Don't Firms Export More? Product Quality and Colombian Plants," Journal of Development Economics, forthcoming.

[10] Clerides, Sofronis, Lach, Saul, and James R. Tybout (1998) "Is Learning by Exporting Important? Micro-Dynamic Evidence from Colombia, Mexico, and Morocco," Quarterly Journal of Economics 113: 903-947.

[11] Das, S. M. Roberts, and J. Tybout (2007) "Market Entry Costs, Producer Heterogeneity, and Export Dynamics," forthcoming in Econometrica. 
[12] Devereux, M., A. Head, and B. Lapham (1996A) "Monopolistic Competition, Increasing Returns, and the Effects of Government Spending," Journal of Money, Credit, and Banking, 28(2), 233-254.

[13] Devereux, M., A. Head, and B. Lapham (1996B) "Aggregate Fluctuations with Increasing Returns to Specialization and Scale," Journal of Economic Dynamics and Control, 20, 627-656.

[14] Eaton, Jonathan, Sam Kortum, and Francis Kramarz (2004a) "Dissecting Trade: Firms, Industries, and Export Destinations," American Economic Review, Papers and Proceedings, 94, No. 2: 150-154.

[15] Eaton, Jonathan, Sam Kortum, and Francis Kramarz (2004b) "An Anatomy of International Trade: Evidence from French Firms," NBER Working Paper 10344.

[16] Ethier, Wilfred J. (1982) "National and International Returns to Scale in the Modern Theory of International Trade," American Economic Review, 72, No. 3: 389-405.

[17] Grossman, G.M. and E. Helpman (1991) Innovation and Growth in the Global Economy, Cambridge, MA: The MIT Press.

[18] Halpern, L. M. Koren, and A. Szeidl (2006) "Imports and Productivity," mimeo, Federal Reserve Bank of New York.

[19] Helpman, Elhanan, Marc J. Melitz, and Stephen R. Yeaple (2004) "Export versus FDI with Heterogeneous Firms" American Economic Review, 94: 300-316.

[20] Kasahara, Hiroyuki, and Joel Rodrigue (2005) "Does the Use of Imported Intermediates Increase Productivity? Plant-Level Evidence," EPRI Working Paper \# 2005-7.

[21] Krugman, Paul (1979) "Increasing Returns, Monopolistic Competition, and International Trade," Journal of International Economics, 9: 469-79.

[22] Liu, Lili (1993) "Entry-Exit, Learning and Productivity Change: Evidence from Chile," Journal of Development Economics, 42: 217-242.

[23] McFadden, Daniel. (1978) "Modeling the Choice of Residential Location," in A. Karlquist et al. (eds.), Spatial Interaction Theory and Residential Location, Amsterdam: NorthHolland. 
[24] Melitz, Mark J.(2003) "The Impact of Trade on Intra-Industry Reallocations and Aggregate Industry Productivity," Econometrica, 71: 1695-1725.

[25] Pavcnik, Nina (2002) "Trade Liberalization, Exit, and Productivity Improvements: Evidence From Chilean Plants," Review of Economic Studies, 69(1): 245-276.

[26] Rodrigue, Joel (2007) "FDI and Exports: An Empirical Framework," mimeo, Queen's University.

[27] Romer, Paul (1987) "Growth Based on Increasing Returns Due to Specialization," American Economic Review, 77(2), 56-62.

[28] Rust, John (1987) "Optimal replacement of GMC bus engines: an empirical model of Harold Zurcher." Econometrica 55(5): 999-1033.

[29] Rust, John (1994) "Estimation of Dynamic Structural Models, Problems and Prospects: Discrete Decision Processes," in C. A. Sims (ed.), Advances in Econometrics Sixth World Congress, Volume II, New York: Cambridge University Press.

[30] Roberts, Mark and James R. Tybout (1997) "Decision to Export in Columbia: An Empirical Model of Entry with Sunk Costs" American Economic Review, 87: 545-564.

[31] Tybout, James R. (1996) "Chile, 1979-1986: Trade Liberalization and its Aftermath," in M. Roberts and J. Tybout (eds.), Industrial Evolution in Developing Countries, Oxford: Oxford University Press.

[32] Trefler, Daniel (2004) "The Long and Short of the Canada-U.S. Free Trade Agreement," American Economic Review, 94(4): 870-895.

[33] Yi, Kei-Mu (2003) "Can Vertical Specialization Explain the Growth of World Trade?" Journal of Political Economy, 111(1): 52-102. 


\section{A Appendix}

\section{A.1 Estimation Procedure}

\section{A.1.1 Type I Extreme-Value Distributions}

Here, we briefly discuss the properties of Type I extreme-value distributed random variables (c.f., Ben-Akiva and Lerman (1985)). Assume that $\epsilon(0)$ and $\epsilon(1)$ are independently drawn from identical extreme-value distributions with mean zero and variance $\frac{\varrho^{2} \pi^{2}}{6}$, where $\varrho$ is the shape parameter. ${ }^{32}$ Let $V(0)$ and $V(1)$ be real numbers. We use the following two properties for our estimation. The first property is:

$$
E[\max (V(0)+\epsilon(0), V(1)+\epsilon(1)]=\varrho \ln [\exp (V(0) / \varrho)+\exp (V(1) / \varrho)],
$$

where the expectation is taken with respect to the distribution of $\epsilon(0)$ and $\epsilon(1)$. The second property is:

$$
P(V(0)+\epsilon(0)>V(1)+\epsilon(1))=\frac{\exp (V(0) / \varrho)}{\exp (V(0) / \varrho)+\exp (V(1) / \varrho)} .
$$

In the multivariate case, when we have $\epsilon(d)$ for $d=0,1,2, \ldots, J$, the first property is $E\left[\max _{j=0,1, \ldots, J} V(j)+\right.$ $\epsilon(j)]=\varrho \ln \left[\sum_{j=0}^{J} \exp (V(j) / \varrho)\right]$ while the second property is $P[V(d)+\epsilon(d)>V(j)+\epsilon(j)$ for all $j \neq d]=$ $\frac{\exp (V(d) / \varrho)}{\sum_{j^{\prime}=0}^{J} \exp \left(V\left(j^{\prime}\right) / \varrho\right)}$.

\section{A.1.2 Initial Distribution Specification}

Following Heckman (1981), we specify the distribution of $\tilde{\eta}$ in 1990 as

$$
\mu_{0, \theta}(\tilde{\eta}, d)=P_{0}^{x}\left(d^{x} \mid \tilde{\eta}\right) P_{0}^{x}\left(d^{m} \mid \tilde{\eta}\right) g_{\tilde{\eta}, 0}(\tilde{\eta})
$$

where $(\sigma-1) \ln \varphi, \ln z^{x}, \ln z^{m}$ are independently normally distributed with means $\mu_{0}^{\varphi}, \mu_{0}^{x}$, and $\mu_{0}^{m}$, and standard deviations $\sigma_{0}^{\varphi}, \sigma_{0}^{x}$, and $\sigma_{0}^{m}$ so that

$$
g_{\tilde{\eta}, 0}(\tilde{\eta})=\frac{1}{\sigma_{0}^{\varphi} \sigma_{0}^{x} \sigma_{0}^{m}} \phi\left(\frac{(\sigma-1) \ln \varphi-\mu_{0}^{\varphi}}{\sigma_{0}^{\varphi}}\right) \phi\left(\frac{\ln z^{x}-\mu_{0}^{x}}{\sigma_{0}^{x}}\right) \phi\left(\frac{\ln z^{m}-\mu_{0}^{m}}{\sigma_{0}^{m}}\right)
$$

\footnotetext{
${ }^{32}$ The cumulative distribution function of $\epsilon(d)$ for $d=0,1$ is $\exp (-\exp (-(\epsilon(d)-\gamma)))$, where $\gamma$ is Euler's constant.
} 
while $P_{0}^{x}\left(d^{x} \mid \tilde{\eta}\right)$ and $P_{0}^{x}\left(d^{m} \mid \tilde{\eta}\right)$ are specified under logit formulas:

$$
\begin{aligned}
P_{0}^{x}\left(d^{x} \mid \eta\right) & =\frac{\exp \left(\alpha_{0}^{x}+\alpha_{1}^{x}(\sigma-1) \ln \varphi+\alpha_{2}^{x} \ln z^{x}+\alpha_{3}^{x} \ln z^{m}\right)}{1+\exp \left(\alpha_{0}^{x}+\alpha_{1}^{x}(\sigma-1) \ln \varphi+\alpha_{2}^{x} \ln z^{x}+\alpha_{3}^{x} \ln z^{m}\right)}, \\
P_{0}^{m}\left(d^{m} \mid \eta\right) & =\frac{\exp \left(\alpha_{0}^{m}+\alpha_{1}^{m}(\sigma-1) \ln \varphi+\alpha_{2}^{m} \ln z^{x}+\alpha_{3}^{m} \ln z^{m}\right)}{1+\exp \left(\alpha_{0}^{m}+\alpha_{1}^{m}(\sigma-1) \ln \varphi+\alpha_{2}^{m} \ln z^{x}+\alpha_{3}^{m} \ln z^{m}\right)} .
\end{aligned}
$$

\section{A.1.3 Estimation of the Density Function}

\section{THIS SECTION NEEDS TO BE CORRECTED AND DETERMINED IF IT IS NECESSARY.}

Conditioning on $\varphi_{i}$, we may compute the estimate of $\omega_{i t}=\left(\omega_{i t}^{r}, \omega_{i t}^{x}, \omega_{i t}^{m}\right)^{\prime}$ from (??)-(??) as

$$
\begin{aligned}
\tilde{\omega}_{i t}^{r}\left(\eta_{i}\right) & =\ln r_{i t}-\alpha_{0}-\alpha_{t}-\ln \left(1+z_{i}^{x}\right) d_{i t}^{x}-\alpha_{m} \ln \left(1+z_{i}^{m}\right) d_{i t}^{m}-(\sigma-1) \ln \varphi_{i}, \\
\tilde{\omega}_{i t}^{x}\left(\eta_{i}\right) & =\ln \kappa_{i t}^{x}-\ln \left[z_{i}^{x} /\left(1+z_{i}^{x}\right)\right], \\
\tilde{\omega}_{i t}^{m}\left(\eta_{i}\right) & =\ln \kappa_{i t}^{m}-\alpha_{m} \ln \left[z_{i}^{m} /\left(1+z_{i}^{m}\right)\right] .
\end{aligned}
$$

Since whether we may observe $\tilde{\omega}_{i t}^{x}$ and $\tilde{\omega}_{i t}^{m}$ or not depends on the export/import choices, we use the following conditional density function to compute the likelihood contribution from revenues and export/import intensities:

$$
g_{\omega}\left(\tilde{\omega}_{i t} \mid d_{i t}\right)= \begin{cases}g_{\omega_{1}}\left(\tilde{\omega}_{1, i t}\right) & \text { for } d_{i t}=(0,0), \\ g_{\omega_{1}}\left(\tilde{\omega}_{1, i t}\right) g_{\omega_{2} \mid \omega_{1}}\left(\tilde{\omega}_{i t}^{x} \mid \tilde{\omega}_{1, i t}\right) & \text { for } d_{i t}=(1,0), \\ g_{\omega_{1}}\left(\tilde{\omega}_{1, i t}\right) g_{\omega_{3} \mid \omega_{1}}\left(\tilde{\omega}_{i t}^{m} \mid \tilde{\omega}_{1, i t}\right) & \text { for } d_{i t}=(0,1), \\ g_{\omega}\left(\tilde{\omega}_{i t}\right) & \text { for } d_{i t}=(1,1),\end{cases}
$$

where $g_{\omega_{1}}(\cdot)$ is a marginal distribution of $\omega_{1, i t}$ while $g_{\omega_{j} \mid \omega_{1}}\left(\cdot \mid \omega_{1, i t}\right)$ is a conditional distribution of $\omega_{j, i t}$ given $\omega_{1, i t}$ for $j=2,3$. Specifically, given the lower triangular Cholesky decomposition of $\Sigma_{\omega}$, we may write $\left(\omega_{1, i t}, \omega_{i t}^{x}, \omega_{i t}^{m}\right)^{\prime} \equiv\left(\lambda_{11} e_{1, i t}, \lambda_{21} e_{1, i t}+\lambda_{22} e_{2, i t}, \lambda_{31} e_{1, i t}+\lambda_{32} e_{2, i t}+\lambda_{33} e_{3, i t}\right)^{\prime}$, where $\lambda_{m, n}$ is the $(m, n)$-th element of $\Lambda_{\omega}$, and $e_{j, i t}$ is independently distributed $N(0,1)$ for all $j, i, t$. Then, $g_{\omega_{j} \mid \omega_{1}}\left(\tilde{\omega}_{j, i t} \mid \tilde{\omega}_{1, i t}\right)=\frac{1}{\sqrt{2 \pi} \lambda_{j j}} \exp \left(-\frac{1}{2}\left(\frac{\tilde{\omega}_{j, i t}-\left(\lambda_{j 1} / \lambda_{11}\right) \tilde{\omega}_{1, i t}}{\lambda_{j j}}\right)^{2}\right)$ for $j=2,3$.

\section{A.1.4 Counterfactual Experiments Procedure}

Denote the equilibrium aggregate price under the parameter $\theta$ by $P(\theta)$. Suppose that we are interested in a counterfactual experiment characterized by a counterfactual parameter vector $\tilde{\theta}$ that is different from the estimated parameter vector $\hat{\theta}$. Recall that we have the following 
relationship between $\alpha_{0}$ and the equilibrium price $P$ :

$$
\hat{\alpha}_{0}=\ln \left[(\Gamma(\sigma-1) / \sigma)^{\sigma-1} R\right]+(\sigma-1) \ln P(\hat{\theta}),
$$

where the aggregate price is explicitly written as a function of $\theta$. At the counterfactual aggregate price $P(\tilde{\theta})$, the coefficient $\alpha_{0}$ takes a value of

$$
\tilde{\alpha}_{0}=\ln \left[(\Gamma(\sigma-1) / \sigma)^{\sigma-1} R\right]+(\sigma-1) \ln P(\tilde{\theta})=\hat{\alpha}_{0}+k(\tilde{\theta}, \hat{\theta})
$$

where

$$
k(\tilde{\theta}, \hat{\theta}) \equiv(\sigma-1) \ln (P(\tilde{\theta}) / P(\hat{\theta}))
$$

represents the equilibrium price change (up to the parameter $(\sigma-1)$ ).

Thus, replacing $\hat{\alpha}_{0}$ with $\tilde{\alpha}_{0}$, we may evaluate the revenue function (??) at the counterfactual aggregate price $P(\tilde{\theta})$ (i.e. at the counterfactual value of $\alpha_{0}$ ):

$r\left(\eta_{i}, d_{i t} ; k(\tilde{\theta}, \hat{\theta})\right)=\exp \left(k(\tilde{\theta}, \hat{\theta})+\hat{\alpha}_{0}+\alpha_{t} t+\ln \left[1+z_{i}^{x}\right] d_{i t}^{x}+\hat{\alpha}_{m} \ln \left[1+z_{i}^{m}\right] d_{i t}^{m}+(\sigma-1) \ln \varphi_{i}\right)$

The equilibrium price change, $k(\tilde{\theta}, \hat{\theta})$, is then determined so that the following equilibrium free entry condition holds:

$$
\hat{f}_{e}=\int V\left(\eta^{\prime}, d_{i t}=(0,0) ; \tilde{\theta}, k(\tilde{\theta}, \hat{\theta})\right) g_{\eta}\left(\eta^{\prime} ; \tilde{\theta}\right) d \eta^{\prime}
$$

Here $V\left(\eta^{\prime}, d_{i t} ; \tilde{\theta}, k(\tilde{\theta}, \hat{\theta})\right)$ is the solution to the Bellman equations (15)-(??) when the revenue function (44) is used to compute profits and $g_{\eta}\left(\eta^{\prime} ; \tilde{\theta}\right)$ is the probability density function from which the initial plant characteristic vector is drawn. ${ }^{33}$

\section{A.2 Additional Maximum Likelihood Estimates}

Table 13 presents the maximum likelihood estimates for the remaining parameters.

\footnotetext{
${ }^{33}$ For every pair $(\tilde{\theta}, \hat{\theta})$, there exists a unique value of $k(\tilde{\theta}, \hat{\theta})$ that satisfies the free entry condition because the value function $V\left(\eta^{\prime}, d_{i t} ; \tilde{\theta}, k(\tilde{\theta}, \hat{\theta})\right)$ is strictly increasing in $k(\tilde{\theta}, \hat{\theta})$.
} 
Table 13: Remaining Maximum Likelihood Estimates

\begin{tabular}{|c|c|c|c|c|c|c|c|c|c|c|c|c|}
\hline Params & \multicolumn{2}{|c|}{ Apparel } & \multicolumn{2}{|c|}{ Plastics } & \multicolumn{2}{|c|}{ Food } & \multicolumn{2}{|c|}{ Textiles } & \multicolumn{2}{|c|}{ Wood } & \multicolumn{2}{|c|}{ Metals } \\
\hline$\varrho^{d}$ & 0.131 & $(0.031)$ & 0.167 & $(0.026)$ & 0.275 & $(0.023)$ & 0.200 & $(0.034)$ & 0.095 & $(0.016)$ & 0.174 & $(0.028)$ \\
\hline$\varrho^{x}$ & 0.268 & $(0.084)$ & 0.448 & $(0.147)$ & 0.523 & $(0.148)$ & 0.679 & $(0.018)$ & 0.044 & $(0.022)$ & 0.129 & $(0.032)$ \\
\hline$\xi$ & 0.059 & $(0.009)$ & 0.037 & $(0.007)$ & 0.056 & $(0.005)$ & 0.038 & $(0.007)$ & 0.071 & $(0.006)$ & 0.040 & $(0.005)$ \\
\hline$\lambda_{11}$ & 0.314 & $(0.003)$ & 0.329 & $(0.005)$ & 0.382 & $(0.002)$ & 0.324 & $(0.003)$ & 0.422 & $(0.005)$ & 0.335 & $(0.003)$ \\
\hline$\lambda_{22}$ & 1.321 & $(0.059)$ & 1.405 & $(0.037)$ & 0.845 & $(0.007)$ & 1.267 & $(0.034)$ & 0.906 & $(0.020)$ & 1.189 & $(0.037)$ \\
\hline$\lambda_{21}$ & -0.253 & $(0.108)$ & -0.006 & $(0.089)$ & -0.001 & $(0.022)$ & -0.321 & $(0.074)$ & -0.185 & $(0.033)$ & -0.416 & $(0.082)$ \\
\hline$\lambda_{33}$ & 0.676 & $(0.017)$ & 0.572 & $(0.007)$ & 0.935 & $(0.011)$ & 0.636 & $(0.009)$ & 0.885 & $(0.057)$ & 0.699 & $(0.015)$ \\
\hline$\lambda_{32}$ & 0.076 & $(0.073)$ & 0.040 & $(0.047)$ & -.020 & $(0.052)$ & -0.027 & $(0.050)$ & 0.069 & $(0.122)$ & -0.026 & $(0.059)$ \\
\hline$\lambda_{31}$ & -0.041 & $(0.059)$ & 0.046 & $(0.026)$ & -0.171 & $(0.033)$ & -0.012 & $(0.033)$ & -0.461 & $(0.085)$ & 0.016 & $(0.033)$ \\
\hline$\lambda_{44}$ & 0.170 & $(0.002)$ & 0.154 & $(0.002)$ & 0.197 & $(0.001)$ & 0.209 & $(0.002)$ & 0.228 & $(0.002)$ & 0.175 & $(0.002)$ \\
\hline$\lambda_{43}$ & 0.023 & $(0.011)$ & 0.012 & $(0.009)$ & 0.011 & $(0.008)$ & 0.009 & $(0.013)$ & 0.014 & $(0.028)$ & 0.018 & $(0.009)$ \\
\hline$\lambda_{42}$ & -0.043 & $(0.010)$ & -0.018 & $(0.011)$ & -0.020 & $(0.005)$ & -0.028 & $(0.012)$ & -0.012 & $(0.012)$ & -0.011 & $(0.010)$ \\
\hline$\lambda_{41}$ & 0.049 & $(0.003)$ & 0.056 & $(0.004)$ & 0.076 & $(0.003)$ & 0.103 & $(0.003)$ & 0.119 & $(0.005)$ & 0.083 & $(0.003)$ \\
\hline$\mu_{0}^{x}$ & -4.080 & $(0.540)$ & -4.769 & $(0.286)$ & -2.730 & $(0.200)$ & -3.921 & $(0.350)$ & -3.211 & $(0.338)$ & -3.975 & $(0.374)$ \\
\hline$\mu_{0}^{m}$ & -1.646 & $(0.147)$ & -1.058 & $(0.159)$ & -3.105 & $(0.142)$ & -1.428 & $(0.116)$ & -3.969 & $(0.723)$ & -1.874 & $(0.148)$ \\
\hline$\mu_{0}^{\varphi}$ & 0.057 & $(0.081)$ & 0.691 & $(0.113)$ & 0.974 & $(0.079)$ & 0.412 & $(0.076)$ & 0.345 & $(0.082)$ & 0.537 & $(0.085)$ \\
\hline$\sigma_{0}^{x}$ & 1.387 & $(0.345)$ & 1.392 & $(0.134)$ & 2.768 & $(0.243)$ & 1.350 & $(0.209)$ & 1.929 & $(0.267)$ & 1.096 & $(0.266)$ \\
\hline$\sigma_{0}^{m}$ & 1.154 & $(0.117)$ & 1.323 & $(0.130)$ & 1.308 & $(0.140)$ & 1.240 & $(0.107)$ & 1.835 & $(0.462)$ & 1.278 & $(0.118)$ \\
\hline$\sigma_{0}^{\varphi}$ & 1.233 & $(0.065)$ & 1.271 & $(0.090)$ & 1.518 & $(0.061)$ & 1.279 & $(0.058)$ & 1.259 & $(0.065)$ & 1.359 & $(0.063)$ \\
\hline$a_{0}^{x}$ & -0.744 & $(1.610)$ & 1.543 & $(2.575)$ & 1.763 & $(0.812)$ & 0.199 & (1.137) & 2.485 & $(2.267)$ & 2.378 & (1.777) \\
\hline$a_{1}^{x}$ & 1.549 & $(0.368)$ & 0.832 & $(0.257)$ & 0.598 & $(0.117)$ & 1.199 & $(0.184)$ & 1.078 & $(0.299)$ & 0.803 & $(0.203)$ \\
\hline$a_{2}^{x}$ & 1.206 & $(0.569)$ & 1.053 & $(0.777)$ & 0.127 & $(0.237)$ & 1.084 & $(0.345)$ & 1.556 & $(0.436)$ & 1.443 & $(0.550)$ \\
\hline$a_{3}^{x}$ & -0.336 & $(0.399)$ & 0.062 & $(0.225)$ & 0.127 & $(0.237)$ & -0.031 & $(0.211)$ & 0.257 & $(0.508)$ & 0.447 & $(0.245)$ \\
\hline$a_{0}^{m}$ & -1.203 & $(1.259)$ & 1.959 & $(2.929)$ & -1.528 & $(0.555)$ & 0.011 & $(0.906)$ & -0.354 & $(1.307)$ & 1.002 & $(1.788)$ \\
\hline$a_{1}^{m}$ & 0.906 & $(0.186)$ & 1.364 & $(0.298)$ & 1.198 & $(0.156)$ & 1.012 & $(0.159)$ & 0.879 & $(0.315)$ & 0.951 & $(0.164)$ \\
\hline$a_{2}^{m}$ & 0.175 & $(0.354)$ & 0.872 & $(0.850)$ & 0.289 & $(0.084)$ & 0.235 & $(0.262)$ & 0.357 & $(0.269)$ & 0.584 & $(0.502)$ \\
\hline$a_{3}^{m}$ & 0.123 & $(0.217)$ & 0.233 & $(0.229)$ & 0.419 & $(0.176)$ & 0.658 & $(0.152)$ & 0.855 & $(0.395)$ & 0.808 & $(0.197)$ \\
\hline$f_{e}$ & \multicolumn{2}{|c|}{4.194} & \multicolumn{2}{|c|}{5.017} & \multicolumn{2}{|c|}{12.963} & \multicolumn{2}{|c|}{4.258} & \multicolumn{2}{|c|}{5.555} & \multicolumn{2}{|c|}{3.764} \\
\hline
\end{tabular}

Notes: Standard errors are in parentheses. The parameters are evaluated units of millions of US dollars in 1990.

\section{A.3 Robustness Exercises}

\section{A.3.1 Non-Stationarity}

This section provides additional details of our procedure to estimate the models with exchange rate shocks and time trends in transport costs. The autoregressive process for exchange rates is implemented in the model using the Tauchen's(1986) method with 10 values of exchange rates, $e_{t} \in\left\{e^{1}, e^{2}, \ldots, e^{10}\right\}$, where we denote the transition probability from $e^{i}$ to $e^{j}$ by $q\left(e^{i} \mid e^{j}\right)$. Specifically, we pick $e^{j}$ 's so that $\ln e^{1}, \ldots, \ln e^{10}$ are uniformly distributed between -0.3 and 0.3 . 
Then, letting $\ln \bar{e}^{i}=\left(\ln e^{i}+\ln e^{i+1}\right) / 2$ for $i=1,2, \ldots, 9$,

$$
q\left(e^{i} \mid e^{j}\right)= \begin{cases}\Phi\left(\left(\ln \bar{e}^{1}-\rho \ln e^{j}\right) / \sigma_{e}\right), & \text { for } i=1, \\ \Phi\left(\left(\ln \bar{e}^{i}-\rho \ln e^{j}\right) / \sigma_{e}\right)-\Phi\left(\left(\ln \bar{e}^{i-1}-\rho \ln e^{j}\right) / \sigma_{e}\right), & \text { for } i=2, \ldots, 9 \\ 1-\Phi\left(\left(\ln \bar{e}^{i}-\rho \ln e^{j}\right) / \sigma_{e}\right), & \text { for } i=10\end{cases}
$$

Now, with the extreme-value distribution assumptions, the expected value functions are recursively computed as follows:

$$
\begin{aligned}
\bar{V}_{t}\left(\tilde{\eta}_{i}, d_{i t-1}, e_{t}\right) & =\varrho^{\chi} \ln \left(\exp (0)+\exp \left(\bar{W}_{t}\left(\tilde{\eta}_{i}, d_{i t-1}, e_{t}\right) / \varrho^{\chi}\right)\right) \\
\bar{W}_{t}\left(\tilde{\eta}_{i}, d_{i t-1}, e_{t}\right) & =\varrho^{d} \ln \left(\sum_{d^{\prime} \in \mathcal{D}} \exp \left(\left[\pi_{t}\left(\tilde{\eta}_{i}, d_{i t-1}, d^{\prime}, e_{t}\right)+\beta \exp \left(\alpha_{t}\right)(1-\xi) \sum_{j=1}^{10} \bar{V}_{t+1}\left(\tilde{\eta}_{i}, d^{\prime}, e^{j}\right) q\left(e^{j} \mid e_{t}\right)\right] / \varrho^{d}\right)\right)
\end{aligned}
$$

To take into account the time-trend in transport cost and differences in growth rates between Chile and the rest of the world, we numerically solve the expected value functions backward starting from $t=100$ down to $t=0$ by initializing $\bar{V}_{100}=0$, where $t=0$ corresponds to the year of 1990 in the sample. To compute the conditional choice probabilities at the realized value of exchange rates, we use the self-approximating properties of the Bellman's equation (cf., Rust (1996)) to approximate the transition probability from the realized value at $t, e_{t}$, for $t=0,1, \ldots, 6$ to a discretized point $e^{j} \in\left\{e^{1}, e^{2}, \ldots, e^{10}\right\}$, again using the Tauchen's(1986) method as:

$$
q_{t}\left(e^{i} \mid e_{t}\right)= \begin{cases}\Phi\left(\left(\ln \bar{e}^{1}-\rho \ln e_{t}\right) / \sigma_{e}\right), & \text { for } i=1, \\ \Phi\left(\left(\ln \bar{e}^{i}-\rho \ln e_{t}\right) / \sigma_{e}\right)-\Phi\left(\left(\ln \bar{e}^{i-1}-\rho \ln e_{t}\right) / \sigma_{e}\right), & \text { for } i=2, \ldots, 9 \\ 1-\Phi\left(\left(\ln \bar{e}^{i}-\rho \ln e_{t}\right) / \sigma_{e}\right), & \text { for } i=10,\end{cases}
$$

where $e_{t}$ represents the realized value of exchange rate at the year $t$.

Using the transition probabilities $\left\{q_{t}\right\}$ and a sequence of value functions $\left\{\bar{W}_{t}, \bar{V}_{t}\right\}$, the conditional choice probabilities at $t=0,1, \ldots, 6$ are computed as:

$$
\begin{aligned}
P_{t, \theta}^{\chi}\left(1 \mid \eta, d, e_{t}\right) & =(1-\xi)\left(\frac{\exp \left(\bar{W}_{t}\left(\eta, d, e_{t}\right) / \varrho^{\chi}\right)}{\exp (0)+\exp \left(\bar{W}_{t}(\eta, d, e) / \varrho^{\chi}\right)}\right) \\
P_{t, \theta}^{d}\left(d^{\prime} \mid \eta, d, e_{t}\right) & =\frac{\exp \left(\left[\pi_{t}\left(\eta, d, d^{\prime}, e_{t}\right)+\beta(1-\xi) \sum_{j=1}^{10} \bar{V}_{t+1}\left(\eta, d^{\prime}, e^{j}\right) q_{t}\left(e^{j} \mid e_{t}\right)\right] / \varrho^{d}\right)}{\sum_{\tilde{d} \in \mathcal{D}} \exp \left(\left[\pi_{t}\left(\eta, d, \tilde{d}, e_{t}\right)+\beta(1-\xi) \sum_{j=1}^{10} \bar{V}_{t+1}\left(\eta, \tilde{d}, e^{j}\right) q_{t}\left(e^{j} \mid e_{t}\right)\right] / \varrho^{d}\right)},
\end{aligned}
$$

where $\bar{V}_{t}(\cdot, \cdot, \cdot)$ and $\bar{W}_{t}(\cdot, \cdot, \cdot)$ are defined in equations (46) and (47), respectively.

The density of initial draws upon successful entry, $g_{t, \theta}^{e}(\tilde{\eta})$, is also year-specific and evaluated 
at $\tilde{\eta}^{k}$ as

$$
g_{t, \theta}^{e}\left(\tilde{\eta}^{k}\right)=\frac{\omega^{k} P_{t, \theta}^{\chi}\left(1 \mid \tilde{\eta}^{k},(0,0)\right)}{\sum_{j=1}^{n_{\eta}} \omega^{j} P_{t, \theta}^{\chi}\left(1 \mid \tilde{\eta}^{j},(0,0)\right)} .
$$

Conditioning on $\tilde{\eta}_{i}$, the likelihood contribution from the observation for plant $i$ in period $t>t_{\text {io }}$ is computed as:

$$
L_{i t}\left(\theta \mid \tilde{\eta}_{i}, d_{i t-1}\right)= \begin{cases}P_{t, \theta}^{\chi}\left(0 \mid \tilde{\eta}_{i}, d_{i t-1}\right) & \text { for } \chi_{i t}=0, \\ \underbrace{P_{t, \theta}^{\chi}\left(1 \mid \tilde{\eta}_{i}, d_{i t-1}\right)}_{\text {Staying }} \underbrace{P_{t, \theta}^{d}\left(d_{i t} \mid \tilde{\eta}_{i}, d_{i t-1}\right)}_{\text {Export/Import }} \underbrace{g_{\omega, \theta}\left(\omega_{i t} \mid \tilde{\eta}_{i}, d_{i t}\right)}_{\text {Revenue/Intensity }} & \text { for } \chi_{i t}=1 .\end{cases}
$$

For the initial period of operation for plant $i, t_{i o}$, the likelihood is given by $L_{i t_{i o}}\left(\theta \mid \tilde{\eta}_{i},(0,0)\right)=$ $P_{t_{i o}, \theta}^{d}\left(d_{i t_{i o}} \mid \tilde{\eta}_{i},(0,0)\right) g_{\omega, \theta}\left(\omega_{i t_{i o}} \mid \tilde{\eta}_{i}, d_{i t_{i o}}\right)$. With these, we can write the likelihood contribution from plant $i$ conditioned on $\left(\tilde{\eta}_{i}, d_{i t_{i o}}\right)$ as $L_{i}\left(\theta \mid \tilde{\eta}_{i}, d_{i t_{i o}}\right)=\prod_{t=t_{i o}+1}^{T_{i}} L_{i t}\left(\theta \mid \tilde{\eta}_{i}, d_{i t-1}\right)$, where $T_{i}$ is the last year in which plant $i$ appears in the data. The likelihood contribution from plant $i$ is determined as:

$$
L_{i}(\theta)= \begin{cases}\sum_{k=1}^{n_{\eta}} L_{i}\left(\theta \mid \tilde{\eta}^{k}, d_{i t_{i o}}\right) \mu_{0, \theta}\left(\tilde{\eta}^{k}, d_{i t_{i o}}\right) & \text { for } t_{i o}=1990 \\ \sum_{k=1}^{n_{\eta}} L_{i}\left(\theta \mid \tilde{\eta}^{k}, d_{i t_{i o}}\right) L_{i t_{i o}}\left(\theta \mid \tilde{\eta}^{k},(0,0)\right) g_{\theta}^{e}\left(\tilde{\eta}^{k}\right) & \text { for } t_{i o}>1990\end{cases}
$$

The parameter vector $\theta$ is estimated by maximizing the log-likelihood function $\mathcal{L}(\theta) \equiv \sum_{i=1}^{\mathcal{N}} L_{i}(\theta)$.

We now explain how we conduct counterfactual experiments in this non-stationary model. First, we compute the fixed entry cost $f_{e}$ using the free entry condition by evaluating the value function at the average value of real exchange rates for 1990-1996 and the time-trend term in 1993:

$$
\hat{f}_{e}=\int \bar{V}_{4}(\eta,(0,0), \bar{e} ; \hat{\theta}, P(\hat{\theta})) g_{\eta}(\eta) d \eta
$$

where $t=4$ corresponds to 1993 while $\ln \bar{e}=(1 / 7) \sum_{t=0}^{7} \ln e_{t}=-0.109$ is the average value of the logarithm of real exchange rates for 1990-1996. Here, the value function has two extra arguments, $\hat{\theta}$ and $P(\hat{\theta})$, explicitly indicating that the value function depends on both the model's parameter $\hat{\theta}$ and equilibrium aggregate price under $\hat{\theta}, P(\hat{\theta})$. By evaluating the model in 1993 and at the average value of real exchange rates during the sample period, the experiment is for the model that is evaluated at the "average" trend term and exchange rate so that it is approximately comparable to that of the basic model without exchange rate shocks.

Second, we conduct a counterfactual experiment of, say, moving from free trade to autarky by changing the parameter values of $f_{x}, f_{m}, c_{x}$, and $c_{m}$ to infinity. We denote the 
parameter value under a counterfactual experiment by $\tilde{\theta}$ which takes the same value as $\hat{\theta}$ except that $f_{x}=f_{m}=c_{x}=c_{m}=\infty$. If we keep the equilibrium aggregate price under $\hat{\theta}$

but change the parameter value from $\hat{\theta}$ to $\tilde{\theta}$, the free entry condition does not hold anymore: $\hat{f}_{e} \neq \int \bar{V}_{4}(\eta,(0,0), \bar{e} ; \tilde{\theta}, P(\hat{\theta})) g_{\eta}(\eta) d \eta$. The equilibrium aggregate price under the counterfactual experiment, denoted by $P(\tilde{\theta})$, satisfies the free entry condition; thus, we can compute the counterfactual aggregate price, $P(\tilde{\theta})$, from the condition $\hat{f}_{e}=\int \bar{V}_{4}(\eta,(0,0), \bar{e} ; \tilde{\theta}, P(\tilde{\theta})) g_{\eta}(\eta) d \eta$.

\section{A.3.2 Alternative Trade Shock Specifications}

In the basic specification, firms draw separate shocks associated with each of the four possible trade statuses. We now examine how sensitive our results are with respect to this shock structure by considering three alternative shock specifications. In what follows, we describe each specification, provide the relevant Bellman's equations and the conditional choice probabilities and present estimates for select parameters and results of counterfactual exercises for Wearing Apparel. Similar results (not reported) were obtained for the remaining industries in our sample.

In the first alternative, firms first receive a shock associated with the decision to trade or not trade. If the firm decides to trade, it then draws shocks associated with each of the three possible export/import statuses. In particular, export and import choices are further partitioned into $\mathcal{D}=\mathcal{D}_{0} \cup \mathcal{D}_{1}$, where $d=(0,0) \equiv \mathcal{D}_{0}$ implies that the firm does not trade and $d \in\{(1,0),(0,1),(1,1)\} \equiv \mathcal{D}_{1}$ is a set of export/import choices when the firm engages in trade. In this model, firms which stay in the market first receive a trade shock associated with the decision to trade or not trade, $\left(\epsilon_{1}^{d}(0), \epsilon_{1}^{d}(1)\right) \equiv \epsilon_{1}^{d}$, where $\epsilon_{1}^{d}(0)$ plus the continuation value of not trading is the return from choosing to not trade and the return from trade is the continuation value of doing so plus $\epsilon_{1}^{d}(1)$. If the firm decides to trade, it then draws idiosyncratic export/import shocks associated with each export/import status given by $\left(\epsilon_{2}^{d}(1,0), \epsilon_{2}^{d}(0,1), \epsilon_{2}^{d}(1,1)\right) \equiv \epsilon_{2}^{d}$. The trade shocks are drawn from an extreme-value distribution with scale parameter $\varrho_{1}^{d}$ while the export/import shocks are drawn from a similar distribution with scale parameter $\varrho_{2}^{d}$.

Using the properties of extreme-value distributions, a firm's optimization problem is recur- 
sively written in terms of the Bellman's equation as

$$
\begin{aligned}
\bar{V}\left(\tilde{\eta}_{i}, d_{i t-1}\right) & =\varrho^{\chi} \ln \left(\exp (0)+\exp \left(\bar{W}_{1}\left(\tilde{\eta}_{i}, d_{i t-1}\right) / \varrho^{\chi}\right)\right) \\
\bar{W}_{1}\left(\tilde{\eta}_{i}, d_{i t-1}\right) & =\varrho_{1}^{d} \ln \left(\sum_{D \in\{0,1\}} \exp \left(\bar{W}_{2}\left(\tilde{\eta}_{i}, d_{i t-1}, D\right) / \varrho_{1}^{d}\right)\right) \\
\bar{W}_{2}\left(\tilde{\eta}_{i}, d_{i t-1}, D\right) & = \begin{cases}\pi\left(\tilde{\eta}_{i}, d_{i t-1},(0,0)\right)+\beta \exp \left(\alpha_{t}\right)(1-\xi) \bar{V}\left(\tilde{\eta}_{i},(0,0)\right), & \text { for } D=0, \\
\varrho_{2}^{d} \ln \left(\sum_{d^{\prime} \in D_{1}} \exp \left(\left[\pi\left(\tilde{\eta}_{i}, d_{i t-1}, d^{\prime}\right)+\beta \exp \left(\alpha_{t}\right)(1-\xi) \bar{V}\left(\tilde{\eta}_{i}, d^{\prime}\right)\right] / \varrho_{2}^{d}\right)\right), & \text { for } D=1,\end{cases}
\end{aligned}
$$

The choice probabilities for all possible current export/import statuses conditional on continuing to operate and the firm's state, $(\eta, d)$, follow the familiar nested logit formula (see, for example, McFadden, 1978) as:

$$
\begin{aligned}
P^{d}((0,0) \mid \eta, d) & =P_{1}^{d}(0 \mid \eta, d) \text { and } \\
P^{d}\left(d^{\prime} \mid \eta, d\right) & =P_{1}^{d}(1 \mid \eta, d)\left[\frac{\exp \left(\left[\pi\left(\eta, d, d^{\prime}\right)+\beta(1-\xi) \bar{V}\left(\eta, d^{\prime}\right)\right] / \varrho_{2}^{d}\right)}{\sum_{\tilde{d} \in\{(1,0),(0,1),(1,1)\}} \exp \left([\pi(\eta, d, \tilde{d})+\beta(1-\xi) \bar{V}(\eta, \tilde{d})] / \varrho_{2}^{d}\right)}\right](54)
\end{aligned}
$$

for $d^{\prime} \in\{(1,0),(0,1),(1,1)\}$, where

$$
P_{1}^{d}(D \mid \eta, d)=\frac{\exp \left(\bar{W}_{2}(\eta, d, D) / \varrho_{1}^{d}\right)}{\exp \left(\bar{W}_{2}(\eta, d, 0) / \varrho^{D}\right)+\exp \left(\bar{W}_{2}(\eta, d, 1) / \varrho_{1}^{d}\right)} \quad \text { for } D=0,1
$$

where $\bar{W}_{2}(\cdot, \cdot, \cdot)$ is given by equation $(52)$.

In Specification (2), a firm first receives an export cost shock, $\left(\epsilon_{1}^{d}(0), \epsilon_{1}^{d}(1)\right) \equiv \epsilon_{1}^{d}$ and makes the decision to export. The firm then receives import cost shocks $\left(\left(\epsilon_{2}^{d}(0), \epsilon_{2}^{d}(1)\right) \equiv \epsilon_{2}^{d}\right.$ if a firm decides to export and $\left(\epsilon_{3}^{d}(0), \epsilon_{3}^{d}(1)\right) \equiv \epsilon_{3}^{d}$ if a firm decides not to export) and makes the decision to import. The export cost shocks are drawn from an extreme-value distribution with scale parameter $\varrho_{1}^{d}$ while the import shocks conditioned on exporting or not exporting are drawn from similar distributions with scale parameter $\varrho_{2}^{d}$ or $\varrho_{3}^{d}$. 
Then a firm's optimization problem is recursively written as

$$
\begin{aligned}
\bar{V}\left(\tilde{\eta}_{i}, d_{i t-1}\right) & =\varrho^{\chi} \ln \left(\exp (0)+\exp \left(\bar{W}_{1}\left(\tilde{\eta}_{i}, d_{i t-1}\right) / \varrho^{\chi}\right)\right) \\
\bar{W}_{1}\left(\tilde{\eta}_{i}, d_{i t-1}\right) & =\varrho_{1}^{d} \ln \left(\exp \left(\bar{W}_{2}\left(\tilde{\eta}_{i}, d_{i t-1}\right) / \varrho_{1}^{d}\right)+\exp \left(\bar{W}_{3}\left(\tilde{\eta}_{i}, d_{i t-1}\right) / \varrho_{1}^{d}\right)\right), \\
\bar{W}_{2}\left(\tilde{\eta}_{i}, d_{i t-1}\right) & =\varrho_{2}^{d} \ln \left(\sum_{d^{\prime} \in\{(1,0),(1,1)\}} \exp \left(\left[\pi\left(\tilde{\eta}_{i}, d_{i t-1}, d^{\prime}\right)+\beta \exp \left(\alpha_{t}\right)(1-\xi) \bar{V}\left(\tilde{\eta}_{i}, d^{\prime}\right)\right] / \varrho_{2}^{d}\right)\right), \\
\bar{W}_{3}\left(\tilde{\eta}_{i}, d_{i t-1}\right) & =\varrho_{3}^{d} \ln \left(\sum_{d^{\prime} \in\{(0,0),(0,1)\}} \exp \left(\left[\pi\left(\tilde{\eta}_{i}, d_{i t-1}, d^{\prime}\right)+\beta \exp \left(\alpha_{t}\right)(1-\xi) \bar{V}\left(\tilde{\eta}_{i}, d^{\prime}\right)\right] / \varrho_{3}^{d}\right)\right) .
\end{aligned}
$$

The corresponding choice probabilities are given by

$$
P^{d}\left(d^{\prime} \mid \eta, d\right)=P_{1}^{d}(1 \mid \eta, d)\left[\frac{\exp \left(\left[\pi\left(\eta, d, d^{\prime}\right)+\beta(1-\xi) \bar{V}\left(\eta, d^{\prime}\right)\right] / \varrho_{2}^{d}\right)}{\sum_{\tilde{d} \in\{(1,0),(1,1)\}} \exp \left([\pi(\eta, d, \tilde{d})+\beta(1-\xi) \bar{V}(\eta, \tilde{d})] / \varrho_{2}^{d}\right)}\right]
$$

for $d^{\prime} \in\{(1,0),(1,1)\}$ while

$$
P^{d}\left(d^{\prime} \mid \eta, d\right)=P_{1}^{d}(0 \mid \eta, d)\left[\frac{\exp \left(\left[\pi\left(\eta, d, d^{\prime}\right)+\beta(1-\xi) \bar{V}\left(\eta, d^{\prime}\right)\right] / \varrho_{3}^{d}\right)}{\sum_{\tilde{d} \in\{(0,0),(1,0)\}} \exp \left([\pi(\eta, d, \tilde{d})+\beta(1-\xi) \bar{V}(\eta, \tilde{d})] / \varrho_{3}^{d}\right)}\right]
$$

for $d^{\prime} \in\{(0,1),(1,0)\}$, where

$$
P_{1}^{d}(1 \mid \eta, d)=\frac{\exp \left(\bar{W}_{2}(\eta, d) / \varrho_{1}^{d}\right)}{\exp \left(\bar{W}_{2}(\eta, d) / \varrho_{1}^{d}\right)+\exp \left(\bar{W}_{3}(\eta, d) / \varrho_{1}^{d}\right)}
$$

and $P_{1}^{d}(0 \mid \eta, d)=1-P_{1}^{d}(1 \mid \eta, d)$, where $\bar{W}_{2}(\cdot, \cdot, \cdot)$ and $\bar{W}_{3}(\cdot, \cdot, \cdot)$ is given by equation (58) and (59), respectively.

The final model, Specification (3), is similar to Specification (2) except that firms make the importing decision first and then the exporting choice. In particular, equations (58)-(59) are replaced with:

$$
\begin{aligned}
& \bar{W}_{2}\left(\tilde{\eta}_{i}, d_{i t-1}\right)=\varrho_{2}^{d} \ln \left(\sum_{d^{\prime} \in\{(0,1),(1,1)\}} \exp \left(\left[\pi\left(\tilde{\eta}_{i}, d_{i t-1}, d^{\prime}\right)+\beta \exp \left(\alpha_{t}\right)(1-\xi) \bar{V}\left(\tilde{\eta}_{i}, d^{\prime}\right)\right] / \varrho_{2}^{d}\right)\right) \\
& \bar{W}_{3}\left(\tilde{\eta}_{i}, d_{i t-1}\right)=\varrho_{3}^{d} \ln \left(\sum_{d^{\prime} \in\{(0,0),(1,0)\}} \exp \left(\left[\pi\left(\tilde{\eta}_{i}, d_{i t-1}, d^{\prime}\right)+\beta \exp \left(\alpha_{t}\right)(1-\xi) \bar{V}\left(\tilde{\eta}_{i}, d^{\prime}\right)\right] / \varrho_{3}^{d}\right)\right)
\end{aligned}
$$


while the conditional choice probabilities are

$$
P^{d}\left(d^{\prime} \mid \eta, d\right)=P_{1}^{d}(1 \mid \eta, d)\left[\frac{\exp \left(\left[\pi\left(\eta, d, d^{\prime}\right)+\beta(1-\xi) \bar{V}\left(\eta, d^{\prime}\right)\right] / \varrho_{2}^{d}\right)}{\sum_{\tilde{d} \in\{(1,0),(1,1)\}} \exp \left([\pi(\eta, d, \tilde{d})+\beta(1-\xi) \bar{V}(\eta, \tilde{d})] / \varrho_{2}^{d}\right)}\right]
$$

for $d^{\prime} \in\{(0,1),(1,1)\}$ while

$$
P^{d}\left(d^{\prime} \mid \eta, d\right)=P_{1}^{d}(0 \mid \eta, d)\left[\frac{\exp \left(\left[\pi\left(\eta, d, d^{\prime}\right)+\beta(1-\xi) \bar{V}\left(\eta, d^{\prime}\right)\right] / \varrho_{3}^{d}\right)}{\sum_{\tilde{d} \in\{(0,0),(0,1)\}} \exp \left([\pi(\eta, d, \tilde{d})+\beta(1-\xi) \bar{V}(\eta, \tilde{d})] / \varrho_{3}^{d}\right)}\right]
$$

for $d^{\prime} \in\{(0,1),(1,0)\}$, where $P_{1}^{d}(1 \mid \eta, d)$ is given by 62 and $P_{1}^{d}(0 \mid \eta, d)=1-P_{1}^{d}(1 \mid \eta, d)$ with $\bar{W}_{2}(\cdot, \cdot, \cdot)$ and $\bar{W}_{3}(\cdot, \cdot, \cdot)$ defined by equation (63) and (64), respectively.

For Wearing Apparel, Tables 14 and 15 present the maximum likelihood estimates for select parameters and the results of counterfactual experiments respectively under these alternative specifications. As can be seen from the tables, the results are very similar to those under the original specification, suggesting that our basic results are not very sensitive to the trade shock structure. SHOULD WE REPORT MORE PARAMETERS AND SHOULD WE ALSO REPORT THE CF FOR AUTARKY.

Table 14: Select Parameter Estimates for Different Trade Shock Specifications for Wearing

\begin{tabular}{|c|c|c|c|c|c|c|c|c|}
\hline Parameters & \multicolumn{2}{|c|}{ Basic Spec. } & \multicolumn{2}{|c|}{ Spec. 1} & \multicolumn{2}{|c|}{ Spec. 2} & \multicolumn{2}{|c|}{ Spec. 3} \\
\hline$\sigma$ & 4.459 & $(0.055)$ & 4.459 & $(0.055)$ & 4.459 & $(0.055)$ & 4.459 & $(0.055)$ \\
\hline$\alpha_{0}$ & -0.791 & $(0.012)$ & -0.791 & $(0.012)$ & -0.794 & $(0.012)$ & -0.792 & $(0.012)$ \\
\hline$\alpha_{t}$ & 0.063 & $(0.0$ & 0.063 & $(0.003)$ & 0.063 & $(0.003)$ & 0.063 & $(0.003)$ \\
\hline$\alpha_{m}$ & 0.249 & $(0.0$ & 0.249 & $(0.058)$ & 0.286 & $(0.063)$ & 0.259 & $(0.062)$ \\
\hline$f$ & 0.044 & $(0.00$ & 0.044 & $(0.008)$ & 0.045 & $(0.009)$ & 0.045 & $(0.008)$ \\
\hline$f^{x}$ & 0.051 & $(0.012)$ & 0.052 & $(0.013)$ & 0.056 & $(0.015)$ & 0.052 & $(0.015)$ \\
\hline$f^{m}$ & 0.037 & $(0.009)$ & 0.037 & $(0.010)$ & 0.041 & $(0.010)$ & 0.036 & $(0.009)$ \\
\hline$c^{x}$ & 0.549 & $(0.1$ & 0.543 & $(0.1$ & 0.444 & $(0$. & 0.516 & $(0.221)$ \\
\hline$c^{m}$ & 0.478 & $(0.1$ & 0.468 & $(0.1$ & 0.595 & $(0.171)$ & 0.505 & $(0.139)$ \\
\hline$\zeta$ & 0.796 & $(0.031)$ & 0.806 & $(0.038)$ & 0.770 & $(0.050)$ & 0.784 & $(0.076)$ \\
\hline Likeli & & 0.59 & & 0.48 & & 9.35 & & $\overline{0.25}$ \\
\hline
\end{tabular}
Apparel

Notes: Standard errors are in parentheses. The parameters are evaluated units of millions of US dollars in 1990.

\section{A.3.3 Eliminating Sunk Costs}

The observed persistence in trade status in the data may be either due to the presence of sunk costs or to plant heterogeneity. To examine the importance of sunk costs in explaining this persistence and its role in our conclusions from the counterfactual exercises, we estimated 
Table 15: Counterfactual Experiments for Different Trade Shock Specifications for Wearing Apparel

\begin{tabular}{|c|c|c|c|c|c|c|c|c|}
\hline & \multicolumn{8}{|c|}{ Counterfactual Experiments } \\
\hline & \multicolumn{4}{|c|}{$\begin{array}{l}\text { No Trade in } \\
\text { Final Goods }\end{array}$} & \multicolumn{4}{|c|}{$\begin{array}{l}\text { No Trade in } \\
\text { Intermediates }\end{array}$} \\
\hline & Basic & Spec 1 & Spec 2 & Spec 3 & Basic & Spec 1 & Spec 2 & Spec 3 \\
\hline$\Delta \ln P$ & 0.014 & 0.015 & 0.013 & 0.014 & 0.020 & 0.020 & 0.025 & 0.021 \\
\hline$\Delta \ln ($ Average $\varphi)$ & -0.011 & -0.010 & -0.011 & -0.011 & -0.010 & -0.010 & -0.010 & -0.010 \\
\hline$\Delta \ln ($ Average TFP $)$ & -0.013 & -0.012 & -0.013 & -0.013 & -0.086 & -0.086 & -0.101 & -0.090 \\
\hline Fraction of Exporters & 0.000 & 0.000 & 0.000 & 0.000 & 0.125 & 0.118 & 0.101 & 0.124 \\
\hline Fraction of Importers & 0.231 & 0.225 & 0.237 & 0.242 & 0.000 & 0.000 & 0.000 & 0.000 \\
\hline Exports & 0.000 & 0.000 & 0.000 & 0.000 & 0.860 & 0.852 & 0.798 & 0.848 \\
\hline Imports & 0.890 & 0.905 & 0.913 & 0.925 & 0.000 & 0.000 & 0.000 & 0.000 \\
\hline
\end{tabular}

models without sunk costs. Tables 16, 17, and 18 report select parameter estimates, transition probabilities, and the results of counterfactual exercises in the model without sunk costs. As can be seen from the second table, the model without sunk costs substantially underestimates the degree of trade status persistence in these industries. We also note that the likelihood ratio tests reject the models without sunk costs. It is interesting to see, however, that the welfare and productivity effects of trade estimated by our counterfactual exercises is similar between the models with sunk costs and the ones without. Most likely, this is because we examine the implications of the models in stationary equilibria where the welfare effects do not generally depend on the relative magnitude of sunk and ongoing fixed costs.

Table 16: Select Parameter Estimates in Model Without Sunk Costs for Wearing Apparel and Food Products

\begin{tabular}{c|cc|cc}
\hline Parameters & \multicolumn{2}{|c|}{ Wearing Apparel } & \multicolumn{2}{|c}{ Food Products } \\
\hline$\sigma$ & 4.481 & $(0.056)$ & 5.234 & $(0.064)$ \\
\hline$\alpha_{0}$ & -1.278 & $(0.013)$ & -0.623 & $(0.016)$ \\
$\alpha_{m}$ & 0.383 & $(0.036)$ & 0.844 & $(0.038)$ \\
$\alpha_{t}$ & 0.064 & $(0.003)$ & 0.034 & $(0.002)$ \\
\hline$f$ & 0.026 & $(0.008)$ & 0.074 & $(0.010)$ \\
$f^{x}$ & 0.026 & $(0.010)$ & 0.076 & $(0.002)$ \\
$f^{m}$ & 0.022 & $(0.007)$ & 0.086 & $(0.004)$ \\
$\zeta$ & 0.908 & $(0.022)$ & 0.950 & $(0.016)$ \\
\hline \hline Log-Likelihood & \multicolumn{2}{|c|}{-4126.50} & \multicolumn{2}{|c}{-10968.82} \\
\hline
\end{tabular}

Notes: Standard errors are in parentheses. The parameters are evaluated units of millions of US dollars in 1990. 
Table 17: Transition Probabilities for Export/Import Status for Model Without Sunk Costs for Wearing Apparel and Food Products

\begin{tabular}{l|cccc}
\hline Wearing Apparel & $\begin{array}{c}\text { No-Export/ } \\
\text { No-Import }\end{array}$ & $\begin{array}{c}\text { Export/ } \\
\text { No-Import }\end{array}$ & $\begin{array}{c}\text { No-Export/ } \\
\text { Import }\end{array}$ & $\begin{array}{c}\text { Export/ } \\
\text { Import }\end{array}$ \\
\hline Actual & & & & \\
No-Export/No-Import & 0.911 & 0.025 & 0.060 & 0.004 \\
Export/No-Import & 0.255 & 0.553 & 0.032 & 0.160 \\
No-Export/Import & 0.244 & 0.015 & 0.676 & 0.065 \\
Export/Import & 0.028 & 0.063 & 0.113 & 0.796 \\
\hline \hline Predicted & & & & \\
No-Export/No-Import & 0.873 & 0.040 & 0.078 & 0.009 \\
Export/No-Import & 0.395 & 0.438 & 0.042 & 0.126 \\
No-Export/Import & 0.444 & 0.024 & 0.450 & 0.082 \\
Export/Import & 0.107 & 0.142 & 0.162 & 0.598 \\
\hline & & & & \\
Food Products & & & & \\
\hline Actual & & & & \\
No-Export/No-Import & 0.876 & 0.056 & 0.062 & 0.006 \\
Export/No-Import & 0.091 & 0.784 & 0.002 & 0.123 \\
No-Export/Import & 0.189 & 0.014 & 0.732 & 0.066 \\
Export/Import & 0.009 & 0.206 & 0.038 & 0.746 \\
\hline \hline Predicted & & & & \\
No-Export/No-Import & 0.810 & 0.129 & 0.048 & 0.013 \\
Export/No-Import & 0.157 & 0.708 & 0.010 & 0.125 \\
No-Export/Import & 0.653 & 0.112 & 0.172 & 0.062 \\
Export/Import & 0.037 & 0.297 & 0.013 & 0.652 \\
\hline
\end{tabular}

Table 18: Counterfactual Experiments for Model Without Sunk Costs: Wearing Apparel and Food Products

\begin{tabular}{l|cccc}
\hline & & \multicolumn{3}{|c}{ Counterfactual Experiments } \\
\hline & $\begin{array}{c}\text { Free } \\
\text { Trade }\end{array}$ & Autarky & $\begin{array}{c}\text { No Trade in } \\
\text { Final Goods }\end{array}$ & $\begin{array}{c}\text { No Trade in } \\
\text { Intermediates }\end{array}$ \\
\hline Wearing Apparel & & & & \\
$\Delta \ln P$ & 0.000 & 0.024 & 0.014 & 0.011 \\
$\Delta \ln ($ Average $\varphi)$ & 0.000 & -0.030 & -0.014 & -0.015 \\
$\Delta \ln ($ Average TFP) & 0.000 & -0.103 & -0.015 & -0.088 \\
Fraction of Exporters & 0.136 & 0.000 & 0.000 & 0.125 \\
Fraction of Importers & 0.190 & 0.000 & 0.180 & 0.000 \\
Exports & 1.000 & 0.000 & 0.000 & 0.919 \\
Imports & 1.000 & 0.000 & 0.903 & 0.000 \\
\hline Food Products & & & & \\
$\Delta \ln P$ & 0.000 & 0.527 & 0.529 & 0.010 \\
$\Delta \ln ($ Average $\varphi)$ & 0.000 & -0.015 & -0.007 & -0.003 \\
$\Delta \ln ($ Average TFP) & 0.000 & -0.064 & -0.007 & -0.052 \\
Fraction of Exporters & 0.510 & 0.000 & 0.000 & 0.511 \\
Fraction of Importers & 0.183 & 0.000 & 0.327 & 0.000 \\
Exports & 1.000 & 0.000 & 0.000 & 0.945 \\
Imports & 1.000 & 0.000 & 0.066 & 0.000 \\
\hline
\end{tabular}

